\title{
On Dialogues, Predication and Elementary Sentences ${ }^{\dagger}$
}

\author{
Shahid Rahman and Nicolas Clerbout*
}

\begin{abstract}
Resumen
En sus orígenes la lógica dialógica constituyó la fundamentación lógica de un nuevo movimiento llamado Escuela de Erlangen o Constructivismo de Erlangen, el que debía proporcionar un nuevo comienzo a una teoría general del lenguaje y de la ciencia. En lo referente a teoría general del lenguaje, la Escuela de Erlangen afirma que el lenguaje no es un hecho que descubrimos, sino una realización cultural humana cuya construcción puede y debe ser controlada. El proyecto de un desarrollo constructivo de un lenguaje científico fue llamado Orthosprache. Desafortunadamente, este proyecto no fue continuado y de alguna manera parecía desvanecerse. Quizás podríamos decir que una de las razones es que los lazos semánticos entre lógica dialógica, que se restringió a la semántica de la constantes lógicas y las aspiraciones lingüísticas más generales de la Orthosprache, no fueron desarrollados suficientemente y, entonces, la nueva teoría del significado de la lógica dialógica parecía haber sido separada del proyecto de establecer una teoría general del significado.

En este artículo nos proponemos presentar una forma posible en la cual una teoría dialógica general del significado podría estar relacionada con lógica dialógica. Más precisamente, el objetivo principal del artículo es establecer las bases para el significado de las frases elementales en el contexto de la interacción dialógica.

PALABRASCLAVE: diálogos, juegos, constructivismo, pragmatismo, lógica dialógica.
\end{abstract}

\begin{abstract}
In its origins Dialogical logic constituted the logical foundations of an overall new movement called the Erlangen School or Erlangen Constructivism that should provide a new start to a general theory of language and of science. In relation to the theory of language, according to the Erlangen-School, language is not just a fact that we discover, but a human cultural accomplishment whose construction reason can and should control. The constructive development of a scientific language was called the Orthospra-

\footnotetext{
$\dagger$ The present paper, based on Rahman/Clerbout/McConaughey 2013a, has been triggered by discussions with Göran Sundholm (Leiden) during his visit as invited professor at the university of Lille and it has been developed in the context of the MESHS-Nord-pas-de Calais-programme Argumentation, Decision; Action (ADA), and the ANR-DFG-Franco-German-project Jurilog. Recibido: octubre 2013. Aceptado: noviembre 2013.

* Université de Lille, UMR 8163: STL.
} 
che-project. Unfortunately, the Orthosprache-project was not further developed and somehow seemed to fade away. Perhaps, one could say that one of the reasons is that the semantic links between dialogical logic, that was restricted to logical constants, and the more general linguistic aspirations of the Orthosprache were not sufficiently developed and then the new theory of meaning of dialogical logic seemed to be cut off from the project of setting the basis for a general theory of meaning.

In the present paper we would like to contribute to precise one possible way in which a general dialogical theory of meaning could be linked to dialogical logic. More precisely, the main aim of the article is to set the basis for the meaning of elementary sentences in the context of dialogical interaction.

KEY WORDS: dialogues, games, logic, constructivism, pragmatism, dialogical logic.

\section{$1 \quad$ Introduction}

As pointed by G. Sundholm $(1997,2001)$ the standard approach to a formal language for the foundations of science turns it an object of meta-mathematical where syntax is linked to semantics by the assignation of truth values to uninterpreted strings of signs (formulae). Many nowadays reconstructions of logical systems of the historic tradition follow this metalogical view on formal languages and the foundations of science that developed by the mid-thirties. However this view does not apply to the father of modern formal logic, namely Frege. It does not apply because in the work before the influence of Hilbert, Gödel, Bernays and Tarski, expressions of a scientific language, constitute a meaningful language that has a content.

The development of fully interpreted languages is one of the main features of nowadays constructive type theory based on the idea to make explicit at object language level the meaning of the terms involved. Such an endeavour is crucial in the context of the study and development of a language for science.

However, before the development of constructive type theory took place, a previous project, called Orthosprache-project linked to the Dialogical Approach to Logic ${ }^{1}$ challenged the approach of the mainstream analytic theory of meaning of their time. The Orthosprache-project and the Dialogical approach to Logic constituted a part of an overall new movement called the Erlangen School or Erlangen Constructivism proposed by the Erlangen Constructivism by 1970. According to the Erlangen-School, language is not just a fact that we discover, but a human cultural accomplishment developed in the context of a (dialogical) interaction and whose construction reason can and should control.

\footnotetext{
${ }^{1}$ A detailed account of recent developments since, say, Rahman (1993), can be found in Rahman/Keiff (2005) and Keiff (2009). For the underlying metalogic see Clerbout (2013). For a textbook presentation: Redmond/Fontaine (2011) and Rückert (2011a). For the key role of dialogic in regaining the link between dialectics and logic, see Rahman/Keff (2010). Keiff (2004a, b) and Rahman (2009) study Modal Dialogical Logic. Fiutek et al. (2010) study the dialogical approach to belief revision. Clerbout/Gorisse/Rahman (2011) studied Jain Logic in the dialogical framework. Popek (2011) develops a dialogical reconstruction of medieval obligationes. For other books see Redmond (2010) - on fiction and dialogic - Fontaine (2013) - on intentionality, fiction and dialogues - and Magnier (2013) - on dynamic epistemic logic (van Ditmarsch et al. 2007) and legal reasoning in a dialogical framework.
} 
Unfortunately, the Orthosprache-project was not further developed and somehow seemed to fade away. Perhaps, one could say that one of the reasons is that the link between dialogical logic and the Orthosprache was not sufficiently developed - in particular the systematic development of dialogues based on the norms built by an Orthosprache were not worked out- and then the new theory of meaning of dialogical logic seemed to be cut off from the project of setting the basis for scientific languages and also from a general theory of meaning.

In the present paper we would like to contribute to precise one possible way in which a general dialogical theory of meaning could be linked to dialogical logic. More precisely, the main aim of the article is to set the basis for the meaning of elementary sentences in the context of dialogical interaction.

\section{The Orthosprache and Constructive Type Theory}

\subsection{Orthosprache}

The term Orthosprache, was dubbed by Paul Lorenzen in 1972, quoted in a footonote of the second edition of the Logische Propädeutik (1972: 73, footnote 1) and discussed in the bible of the Erlangen School: Konstruktive Logik, Ethik und Wissenschaftstheorie (Schwemmer/Lorenzen, 1975). The idea behind is the explicit, and constructive development by example (exemplarisch) of a language in order to build a targeted scientific terminology (Kamlah/Lorenzen, 1972: 70-111).

The qualification by example refers to one of the major tenets of the overall philosophy of language of the Erlangen School, namely the idea that we grasp an individual as exemplifying something - type theoreticians will say as exemplifying a type (see below):

Yet even science cannot avoid the fact that things do not proffer themselves everywhere as different of their own accord, more often in important areas (e.g. in the social or historical sciences) ... science must decide for itself what it wants to regard as of the same kind and what is of different kind, and address them accordingly.

[...]

As we have said already, the world does not "consist of objects" (of "things in themselves") which are subsequently named by men....

[...]

In the world being disclosed to us all along through language we tend to grasp the individual object as individual at the same time that we grasp it as specimen of [in the orginal: als Exemplar von. S.R.)... Further, when we say "This is a bassoon" we mean thereby "this instrument is a bassoon" ... or when we say, this is "This is a blackbird", we presuppose that our discussion partner already knows "what kind of an object is meant", that we are talking about birds (Kamlah/Lorenzen, 1984: 37). ${ }^{2}$

\footnotetext{
2 Doch auch sie [die Wissenschaft] kann nicht vermeiden, dass ihr die Dinge nicht überall von sich her als
} 
Accordingly the Predicators ${ }^{3}$ of the Ortoshprache are introduced by the study of exemplification instances. Now, as already pointed out by Henri Poincaré in his disputes with the "logicians" a scientific terminology does not only consist on a set or predicators or even of sentences expressing propositions but an adequate scientific language constitutes a system of conceptual interrelations. ${ }^{4}$ The main logical device of the Orthosprache project is to establish the corresponding transitions by Predicator- rules that norm the passage from one to Predicator to the other. Moreover, these transition rules are formulated within a dialogical frame so that given the predicator rule:

$$
\mathrm{X} \varepsilon \mathrm{A} \Rightarrow \mathrm{X} \varepsilon \mathrm{B}
$$

(where $\mathrm{x}$ is a free variable and " $\mathrm{A}$ " are " $\mathrm{B}$ " are predicators) if a player brings forward an object of which predicator A is said to apply then he must also committed to ascribe the predicator B to the same object such as if someone claims $k$ is a bassoon then he is committed to the further claim that $k$ is a musical instrument (where $\mathrm{k}$ is a logical constant - in the Logisch Propädeutik the application of these norms proceeds by substituting individual constants for free variables). The Constructivists of Erlangen called such transition rules that structure a (fully interpreted) scientific language by setting the

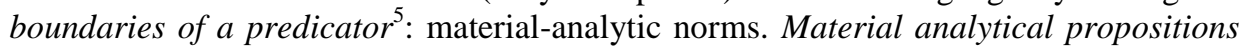
(or more literally material analytical truths) are defined as those universally quantified propositions based on such material-analytic norms (Schwemmer/Lorenzen, 1975: 215). The point of the material-analytic truths is that they establish the link between a conceptual structure and the logical reasoning based on it.

So far so good, but if the challenge should really contest the metalogical approach mentioned above; the idea is that the conceptual structure as developed by predicator rules is not an underlying metalogical structure over which reasoning takes place but rather it is a structure that it is at the surface in the object language level and can accordingly be contested and defended at the same object-language in which a given proposition is proven and the meaning of which is constituted by elements of the structure.

verschieden anbieten, dass sie vielmehr auf wichtigen Gebieten (z.B. in der Sozial- oder in der Geschichtswissenschaft) ihrerseits entscheiden muss, was sie als gleichartig und sie als verschiedenartig ansehen und demgemäß ansprechen will.

$[\ldots]$

Die Welt besteht, wie schon gesagt, nicht aus Gegenständen (aus "Dingen an sich") die erst nachträglich durch den Menschen benannt würden...

$[\ldots]$

In unserer sprachlich schon immer erschlossenen Welt erfassen wir das Einzelding auch als ein solches in der Regel zugleich schon als Exemplar von .... Ferner, wenn wir sagen "dies ist ein Fagott", so meinen wir "dieses Instrument ist ein Fagott" ... oder wenn wir sagen " dies ist eine Amsel", so setzen wir voraus, dass der Gesprächspartner schon weiß, "was für ein Gegenstand" gemeint ist, dass von "Vögeln" die Rede ist. (Kamlah/Lorenzen, $1972: 49-50$ )

3 The use of the terminology predicator, introduced by Carnap in Meaning and Necessity $1947: 6$ ), instead of predicate should avoid the confussion with the grammatical notion.

4 Cf. Poincaré, 1902 and 1906a 1906b and Detlefsen, 1992.

5 Interesting is that the Erlangen School already mentioned cases of vagueness as arising because of the difficulty to set fix boundaries (Kamlah/Lorenzen, $1972: 46-49$ ). 
In order to implement this aim we will make use of constructive type theory, let me thus now introduce very briefly the main features of this approach relevant for the purposes of our paper.

\subsection{Constructive Type Theory and Orthosprache}

Within Per Martin-Löf's constructive type theory (for short CTT) the logical constants are interpreted through the Curry-Howard correspondence between propositions and sets. A proposition is interpreted as a set whose elements represent the proofs of the proposition. It is also possible to view a set as a problem description in a way similar to Kolmogorov's explanation of the intuitionistic propositional calculus. In particular, a set can be seen as a specification of a programming problem, the elements of the set are then the programs that satisfy the specification (Martin-Löf, 1984: 7). Furthermore in CTT sets are understood also as types so that propositions can be seen as data (or proof)-types. ${ }^{6}$

The general philosophical idea is linked to the fully interpreted approach mentioned above and in particular to avoid - in Martin-Löf's (1984: 2) own words - keeping content and form apart. Instead we will at the same time display certain forms of judgement and inference that are used in mathematical proofs and explain them semantically. Thus, we make explicit what is usually implicitly taken for granted. In relation to the explicitation task, it involves to bring into the object level features that determine meaning and that are usually formulated at the metalevel.

According to CTT view on logic the premises and conclusion of a logical inference are not propositions but judgements.

A rule of inference is justified by explaining the conclusion on the assumption that the premisses are known. Hence, before a rule of inference can be justified, it must be explained what it is that we must know in order to have the right to make a judgement of any one of the various forms that the premisses and conclusion can have (Martin-Löf,1984: 2).

The original work of Martin-Löf had as main aim to reconstruct (in the best possible way) informal mathematical reasoning, though as already mentioned, Aarne Ranta (1994) started to apply CTT as a general theory on meaning and extended its use for the study of natural languages.

\subsubsection{Kinds as Types}

In order to see the link between CTT and the project of an Orthosprache, let us start by studying two basic tenets of CTT, namely

\footnotetext{
${ }^{6}$ Cf. Nordström/Petersson/Smith (1990), Granström (2011).
} 
- No entity without type

- No type without identity

The first tenet is strikingly close to the claim of Erlangen Constructivism quoted in 2.1 that we tend to grasp an individual as instantiation of a kind. Accordingly, we can take the assertion that an individual is an element of the set $\mathrm{A}$ as the assertion that an individual instantiates or exemplifies type A. But what is a type A and how do we differentiate between examples and those that are not? Or more fundamentally, what is it that we must know in order to have the right to judge something to be a type?

Those objects that are of the type set are defined in CTT by means of defining their canonical elements, those that "directly" exemplify the type, and the non-canonical ones, those that can be shown using some prescribed method of transformation that they are equal (in the type) to a canonical one: the precise requirement is that the equality between objects of a type must be an equivalence relation. ${ }^{7}$ The latter is what the second tenet is about: the introduction of an equivalence relation in a set (an object of the type set) and certainly it relates to Kamlah/Lorenzen's words quoted above about the need to specify what is same and what is different in a kind. ${ }^{8}$

When we have a type, we know from the semantic explanation of what it means to be a type what the conditions are to be an object of that type. So, if A is a type and we have an object $b$ that satisfies these conditions then $\mathrm{b}$ is an object of type A, which we formally write $b:$ A. ${ }^{9}$ Accordingly,

$$
b: \mathrm{A} \quad \text { A true }
$$

can be read as

$$
\begin{aligned}
& b \text { is an element of the set A } \\
& b \text { is a proof of the proposition A } \\
& b \text { fulfils the expectation A } \\
& b \text { is a solution to the problem A }
\end{aligned}
$$
A has an element
A is true
A is fulfilled
A has a solution

It is essential to distinguish between the proof-object $b$, the type A, (proposition if it is of the type proposition, set if it is of the type underlying a quantification) and the judgement $b: \mathrm{A}$, which establishes that, in this example, $b$ is a proof-object for the proposition A (if A is a proposition). In standard logic, that there is a proof for a given proposition is expressed at the metalanguage level. The fact that there is something (an object) $b$ that grounds the proposition that John is the murderer (yielding the corresponding assertion) is given in the usual analysis at the metalanguage level.

\footnotetext{
${ }^{7}$ For a thorough discussion see Granström (2011: 54-76).

${ }^{8}$ Cf. Kamlah/Lorenzen, (1984 : 37).

${ }^{9}$ Martin-Löf used the sign " $\in$ " in order to indicate that something, say a, is of type, say, B. He even suggests to understand it as a the copula 'is', also Nordström/Petersson/Smith (1990) make use of this notation while other authors such as Ranta (1994) use the colon. Granström (2011) distinguishes the colon from the epsilon, where the first applies to non-canonical elements and the latter to canonical ones. We will use the colon.
} 
Let us now switch to the Orthosprache project. What we are hinting at should be clear: to suggest that the role that plays the exemplarische introduction of predicators in the Orthosprache is played here (in CTT) by the explicit definition of types, and more precisely those types that provide the base for the universally quantified materialanalytic norms are of the type set.

Furthermore, we would like to invite to explore the possibilities of reconstructing the idea of grasping an object as a kind starting by the real definition of the objects that instantiate the type set as in CTT. Set does not instantiate the type set, since we do not have a general method to generate all possible ways to build a set. However, given the type set we can build the objects that instantiate it by the means described above. Accordingly set(-objects) are not primitive either in CTT, since in fact they instantiate the type set. And each of these instantiations is generated by means of its canonical elements and of rules. After such a set(-object) is generated, certain propositional functions on it are defined by means of hypothetical judgements and the introduction of separated subsets - as discussed in the next section.

Moreover, the type set is one of an infinite number of types. There are other types, such as the type prop. In fact predicators are defined by the interaction of these two types, the ontological type set and the type of 'prop' which is about what is said. If we follow this path the distinction between canonical and non-canonical elements and the requirement of a method by which a non-canonical element can be computed so that the result is a canonical element seem an insightful addendum to the project of the constructive development of an Orthosprache for sciences. According to this suggestion, grasping an object as exemplifying a kind does not only introduce the difference between paradigmatic and non-paradigmatic examples: we also need to describe a computation method that carries from paradigmatic to non-paradigmatic ones.

The computation method seems to work straight away for mathematics but it is less clear-cut for other sciences or for types in natural language such as the type city. J. G. Granström (2011: 14-15 and 86-91) suggests to link the distinction between canonical and non-canonical with the difference between mediate concepts, such as in the capital of France, and immediate concepts such as Paris - in the context of establishing the reference of the elements of the set City. Moreover, this involves the use of a computational method by means of which computing the capital of France gives the value Paris which is a canonical element of the set City. ${ }^{10}$ It is still not clear how to work up thoroughly the details of such a computation device. ${ }^{11}$ Ranta (1994: 54-55), while discussing the criticisms against the fruitfulness of applying CTT to natural language, writes:

\footnotetext{
${ }^{10}$ This in fact has been suggested to the authors in a personal email by Granström.

${ }^{11}$ One other strategy would be to differentiate between what Martin-Löf (1984:11-13) calls categories and sets, the former do not require exhaustive definitions of their objects and can be thought as capturing the idea behind properties of individuals. Accordingly, we could either reconstruct a kind as an exhaustive formulation of a type (involving the distinction between paradigmatic and non paradigmatic examples) - that corresponds to the constructive definition of a set - or we could reconstruct a kind as a non exhaustive formulation of a type - corresponding to a category. However, understanding properties of individuals as categories seems to give up the constructivist project of an Orthosprache. Note that, as pointed out by Martin-Löf (1984 : 12), one can quantify over sets but not over categories. Martin-Löf also remarks that one of the problems of Russell's type-theory is confusing both. In fact Russell's ramified types correspond to sets while simple types correspond to categories.
} 
The third way to justify everyday objects in type theory, and the most modest one, is to study delimited models of language use, 'language games'. Such a 'game' shows, in an isolated form, some particular aspect of the use of language, without any pretension to covering all aspects. It is a model of language in the sense in which theories are models of nature. In such a model, the term man is interpreted as some set like \{Matthew, Mark, Luke, John\}, whose elements are fully presented by the canonical names Matthew, etc. (The set could of course be considerably larger, for example, a record of one million names, dates of birth, professions, hobbies.) The model does not present fully present men in blood an flesh, with complete stories of life, but it is enough for the formalization of a fragment of language that does not appeal to any further structure of men)

Indeed, it looks sensible to restrict the sets of quantification for empirical objects to some finite sets. Two of the points of the present paper is to pick up the idea of language games in a logical frame, namely the dialogical one, and bring into consideration a net of such language games.

The first point is linked with the fact that dialogical logic has been developed in the interface between constructive logic and Wittgenstein's language games and the second point involves the idea that the relative under-determination of a set of quantification might be minimized by establishing a structure of such sets that results from norms that rule the passage from one of these sets to the other. This takes us to the notion of predicator rules within the CTT-framework.

\subsubsection{Propositional Functions and Predicator Rules and Dialogues}

\section{Hypothetical and Propositional Functions}

The judgements we have introduced so far do not depend on any assumptions. They are categorical judgements. The CTT-language has also hypothetical judgements of the form

\section{A type $(\mathrm{x}: \mathrm{C})$}

Where $\mathrm{C}$ be a type which does not depend on any assumptions and $\mathrm{A}$ is a type when $\mathrm{x}: \mathrm{C}$ (the context or hypothesis for A)

A case of hypothetical judgements are functions from A to $\mathrm{C}$ :

$$
f(x): A(x: C)
$$

It can be read in several ways, for example:

$\mathrm{f}(\mathrm{x})$ : A for arbitrary $\mathrm{x}: \mathrm{C}$

$\mathrm{f}(\mathrm{x})$ : A under the hypothesis $\mathrm{x}: \mathrm{C}$

$\mathrm{f}(\mathrm{x})$ : A provided $\mathrm{x}: \mathrm{C}$ 


$$
\begin{aligned}
& \mathrm{f}(\mathrm{x}): \text { A given } \mathrm{x}: \mathrm{C} \\
& \mathrm{f}(\mathrm{x}): \text { A if } \mathrm{x}: \mathrm{C} \\
& \mathrm{f}(\mathrm{x}): \text { : } \text { in the context } \mathrm{x}: \mathrm{C}
\end{aligned}
$$

In addition to domains of individuals, an interpretation of a scientific language requires propositions. They are introduced in CTT by laying down what counts as proof of a proposition. Accordingly, a proposition is true if there is such a proof. We write

$$
\text { A: prop }
$$

to formalize the judgement that $\mathrm{A}$ is a proposition. Propositional functions are introduced by hypothetical judgements. The hypothetical judgement required to introduce propositional functions is:

$$
\mathrm{B}(\mathrm{x}): \operatorname{prop}(\mathrm{x}: \mathrm{A})
$$

that reads, $B(x)$ is of the type proposition, provided it is applied to elements of the (type)set $A$. The rule by which we produce propositions from propositional functions is the following:

$$
\begin{aligned}
& a: \mathrm{A} \quad \mathrm{B}(\mathrm{x}): \operatorname{prop}(\mathrm{x}: \mathrm{A}) \\
& \mathrm{B} a: \text { prop }
\end{aligned}
$$

And it requires also of the formulation of an appropriate rule that defines the equivalence relation within the type prop:

$a=b: \mathrm{A} \quad \mathrm{B}(\mathrm{x}): \operatorname{prop}(\mathrm{x}: \mathrm{A})$
$\mathrm{B} a=\mathrm{B} b:$ prop

Let us focus our attention to the first rule. A crucial point is here that in CTT the distinction is drawn between two forms of judgement involving $a$ is $B$, namely:

and

$$
a: \mathrm{B}
$$

\section{$\mathrm{B} a$}

The first concerns the relation between an element and a set and the second asserts a proposition. Moreover, the conclusion of the rule does not say that the proposition is true , it only says that is a proposition - since the rule only lays down the condition to produce a proposition from a propositional function.

Such a confusion of types is clear in simple examples of quantification: If I assert

There are small elephants 
The naif first-order interpretation, there are $x$ that are small and elephants is simply wrong:

Elephant is the domain over which the propositional function small is defined, thus elephant is of the type of a set of quantification and small a function that yields a proposition provided the function is applied to the domain:

That is instead of

$$
\exists x(L x \wedge S x)
$$

We should have

$$
\text { ( } \exists \mathrm{x}: \mathrm{L}) \mathrm{Sx} \text { (provided Sx: prop, under the proviso that } \mathrm{x}: \mathrm{L} \text { ) }
$$

Such kind of rules, called formation rules, embody at the same the syntax and the explanation of the basic types that provide the meaning of the language (involving logical constants and non logical ones). Another way of looking at the rules is to say that the formation rules explain the types of the language and that the introduction and elimination rules explain the typing rules for expressions - see the formation rules for each logical constant of intuitionist first order logic in appendix I. To the formation, the introduction and the elimination rules come computation rule explaining the dynamics of the typing. One of the most distinctive features of CTT is that before the logical process starts the formation rules should be applied: this is the way that CTT implements the idea of fully interpreted language. In fact, the process of the application of the formation rule proceeds bottom up: from the expression to be proved to the meaning elements of it.

To give a flavour of the use of the formation rules:

Let us assume that the task is to prove that the following holds

$$
\text { (0) } \quad \mathrm{B} a \rightarrow \exists \mathrm{xBx}
$$

or to write it down in the explicit language of CTT

$$
\text { (1) } \mathrm{B} a \rightarrow(\exists \mathrm{x}: \mathrm{A}) \mathrm{Bx} \text { true }
$$

It if it is true it must be a proposition

So we must have before

$$
\text { (2) } \quad \mathrm{B} a \rightarrow(\exists \mathrm{x}: \mathrm{A}) \mathrm{Bx}: \text { prop }
$$

The left part is a prop if head and tail of the conditional are also propositions:
(3)
Ba: prop
(4)
( $\exists x:$ A)Bx: prop 
If the first is a prop then there must be some set such $a$ is an element of that set and a propositional function $\mathrm{B}(\mathrm{x})$ such that it is a prop (i.e., is of the type proposition) provided that $\mathrm{x}$ ranges over that set, let us take that the set is A.:

$$
\text { (5) } \quad a: \mathrm{A} \quad \text { (6) } \quad \mathrm{B}(\mathrm{x}): \operatorname{prop}(\mathrm{x}: \mathrm{A})
$$

Similarly the formation of 4 requires A to be a set of that set and a propositional function $\mathrm{B}(\mathrm{x})$ such that is a prop provided that $\mathrm{x}$ ranges over $\mathrm{A}$. One can now proceed by checking the constitution rules of A. Let us consider that we know how A has been defined and that $a$ is indeed of type A and continue with the existential sentence. Now that we know what we are talking about we can proceed with the proof.

This notion of propositional function as hypothetical judgement allows the (intensional) introduction of subsets by separation:

$$
\begin{array}{ll}
\mathrm{A}: \text { set } \mathrm{B}(\mathrm{x}): \operatorname{prop}(\mathrm{x}: \mathrm{A}) & b: \mathrm{A} \quad \mathrm{B}(b) \text { true } \\
\hdashline \mathrm{x}: \mathrm{A} \mid \mathrm{B}(\mathrm{x})\}: \text { set } & b:\{\mathrm{x}: \mathrm{A} \mid \mathrm{B}(\mathrm{x})\}
\end{array}
$$

This explanation of subsets also justifies the following rules

$$
\begin{array}{cc}
b:\{\mathrm{x}: \mathrm{A} \mid \mathrm{B}(\mathrm{x})\} & b:\{\mathrm{x}: \mathrm{A} \mid \mathrm{B}(\mathrm{x})\} \\
\hline-b: \mathrm{A} & \mathrm{B}(b) \text { true }
\end{array}
$$

Since this method is based on pre-existent sets that have been constructed by description of its canonical elements, the standard paradoxes of set theory do not appear (such paradoxes also appear in some early formulations of the Lorenzen's method for the construction of sets) $)^{12}$.

\section{Predicator Rules}

Let us switch now once more to the Orthosprache project. On our view, the rule that produces a proposition from a propositional function and a set (as type) reconstructs the predicate rule in the context of CTT and renders the form of a basic predicator rule. The main idea here is that a predicator is defined over an object that instantiates the type set. Predicators, according to the Erlangen School, introduce a classification method in a domain. This is what hypothetical judgements such as $\mathrm{B}(x)$ : prop $(x: \mathrm{A})$ express. According to this reconstruction, we produce a proposition from a predicator $\mathrm{B}(x)$ that is introduced with the help of A that is of the type set and that set A is defined by rendering its paradigmatic examples and generation method.

\footnotetext{
12 Cf. Siegwart (1993).
} 
This reconstruction is closer to the beautiful analysis of Lorenz and Mittelstrass (1967) of Plato's Cratylus. Particularly so, since such an analysis launches the Erlangen project of a structure of predicator rules. Indeed, in the paper mentioned above the authors point out to basic different acts of predication, namely naming (óvo $\mu \dot{\alpha} \zeta \epsilon i v$ ) and stating $(\lambda \dot{\epsilon} \gamma \in \dot{\epsilon})$. The first one amounts to the act of subsuming one individual under a concept and the latter establishes a true proposition. Naming is about correctness: one individual reveals the concept it instantiates if the naming is correct (names reveal objects for what they are):

Names, i.e. predicates, are tools with which we distinguish objects from each other. To name objects or to let an individual fall under some concept is on the other hand the means to state something about objects, i.e. to teach and to learn about objects, as Plato prefers to say.

[...] whereas only 'correct' names reveal objects for what they are (Crat. 422d), i.e. place individuals under an appropriate concept. (Lorenz/Mittelstrass, 1967: 7).

Stating is about the truth of the proposition that results of this kind of predication act. If an individual is indeed an element of the adequate type subset separated by the predicate at stake the associated sentence is true. We believe this is a fair reconstruction of the following lines of Lorenz/Mittelstrass (1967: 8):

Therefore, in Plato's terminology, a name is correct or reveals an object, if the associated elementary sentence is true, and incorrect if the associated elementary sentence is false.

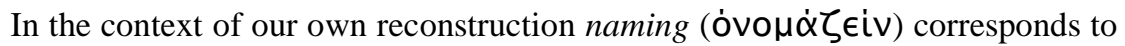
the assertions that an individual is an element of a given set. That is, it involves judgements of the form

$$
b: \mathrm{A},
$$

and stating $(\lambda \dot{\epsilon} \Upsilon \in \dot{\imath} V)$ corresponds to building a proposition given the adequate elements of a set, that is

$\mathrm{B} b$ (where $b:$ A separated by $\mathrm{B} x$ ).

Thus, there is a relation between correctness and truth. But on our view correctness corresponds to the fact that an object can be shown to be an element of the set and this leads to judgement $b:$ A. Then such a judgement provides the basis on which an associated proposition - here $\mathrm{B} b-$ is said to be true.

The original predicator rule that regulates the transition from one propositional form to the other can be seen as a more complex prescription that might be reconstructed, for example in the following form:

$$
\operatorname{Gourmand}(z): \operatorname{prop}(z:\{x: \operatorname{Men} \mid \operatorname{French}(x)\})
$$


provided Men is a set and $\operatorname{French}(x)$ a propositional function that yields a prop when $x$ ranges over Men.

Thus Gourmand $(z):$ prop $(z:\{x: \operatorname{Men} \mid \operatorname{French}(x)\})$ reads: the predicator Gourmand produces a proposition provided that it is applied to those men to whom the predicator French applies.

The point is how to relate this with Dialogues. This is the issue of the following paragraphs.

\section{$3 \quad$ Predicator Rules and Dialogues: First Steps}

Let us start with a presentation of the underlying intuitions. As already mentioned, given a transition rule such as

$$
x \varepsilon \mathrm{A} \Rightarrow x \varepsilon \mathrm{B}
$$

we have: if a player brings forward an object of which predicator A is said to apply then he must also be committed to ascribe the predicator B to the same object.

In the context of Basic Predicator Rules and of the distinctions of the two forms of predication discussed in the preceding paragraphs, we could distinguish between the basic predicator formation rules and the basic predicator rules. The former ones concern the formation rules on which the latter are based on. In other words, we should distinguish between:

A $x: \operatorname{prop}(x: \mathrm{B})$

(Ax constitutes a proposition provided that $\mathrm{x}$ is an element of $\mathrm{B}$ )

and

$$
\mathrm{p}: \mathrm{A} x(x: \mathrm{B})
$$

( $\mathrm{p}$ constitutes a play for Ax, provided $x$ is an element of the set B)

The following illustrates the way these expressions would be handled in a dialogical setting (see a more detailed explanation in the next Section):
1. $\mathrm{X} ! \mathrm{p}: \mathrm{A} \tau$
2. Y ?type $(Y$ asks for the type)
3. $\mathrm{X}$ ! A $\tau$ : prop ( $\mathrm{X}$ answers that it is of the type proposition)
4. $\mathrm{Y} ?_{\mathrm{F}}(\mathrm{Y}$, asks for the formation rule $)$
5. X! Ax: prop $(x: \mathrm{B})$

If we take a simplified version of the example of the Frenchmen mentioned above, the point of these rules is that if player X posited that the individual $k$ is a Gourmand and if this presupposes that Gourmand $(x)$ is a proposition when $x$ is French, then this commits $\mathrm{X}$ to posit that Gourmand $(k)$ is a proposition if $k$ is French. Now a continuation after line 5 could be:

$\mathrm{Y} ? \tau: \mathrm{B}$ (Y asks to apply the propositional function Ax to $\tau$, where $\tau$ occurs in A) $\mathrm{X} ! \mathrm{A} \tau:$ prop 
The last line, being identical to line 3 above, seems to trigger a new cycle. However this is not the case: this time, $\mathrm{X}$ 's posit is grounded by the very fact that $\mathrm{Y}$ admitted that $\tau$ is a B when he asked $\mathrm{X}$ to apply Ax to it. As we will see below, this possibly confusing situation is actually prevented in the dialogical setting by the use of the formal rule for material-analytic dialogues.

Now the (material) dialogue might continue by asking for the formation rule of the set $\mathrm{B}$. The defender must then provide:

- the canonical elements

- an algorithm that shows how to compute non canonical from canonical ones (in non mathematical contexts an exhaustive enumeration might be sufficient)

- rules that determine the equivalence class correspondent to the set

In addition to the formation rules, we need to have basic predicator rules that should provide the concessions from which a play for the correspondent elementary sentence can be produced (if the elementary sentence happens to be true).

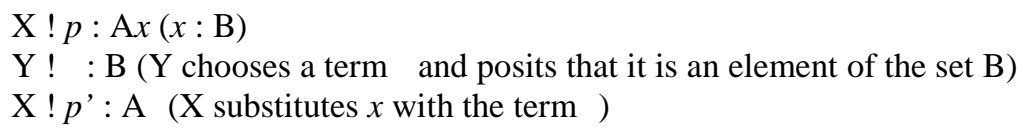

If we develop material-analytic dialogues, elementary sentences can be challenged: by the formation rules and the applications of adequate conceded predicator rules (if there are any such concessions). The idea behind the material-analytic dialogues is that, as in formal dialogues, O's elementary sentences cannot be challenged whereas $\mathbf{O}$ can challenge an elementary sentence (posited by $\mathbf{P}$ ) iff himself (the Opponent) did not posit it before.

The case where separated subsets are at stake can be developed analogously. In the next Section we come back to these issues with more details and explanations.

\section{$4 \quad$ Predicator Rules and Material-Analytic Dialogues}

The dialogical approach to logic is not a specific logical system but rather a rule-based semantic framework in which different logics can be developed, combined and compared. An important point is that the rules that fix meaning are of more than one kind. This feature of its underlying semantics quite often motivated the dialogical approach to be understood as a pragmatist semantics. More precisely, in a dialogue two parties argue about a thesis respecting certain fixed rules. The player that states the thesis is called Proponent $(\mathbf{P})$, his rival, who contests the thesis is called Opponent $(\mathbf{O})$. In its original form, dialogues were designed in such a way that each of the plays end after a finite number of moves with one player winning, while the other loses. Actions or moves in a dialogue are often understood as speech-acts involving declarative utterances or posits and interrogative utterances or requests. The point is that the rules of the dialogue do not operate on expressions or sentences isolated from the act of uttering them. The rules are divided into particle rules or rules for logical constants 
(Partikelregeln) and structural rules (Rahmenregeln). The structural rules determine the general course of a dialogue game, whereas the particle rules regulate those moves (or utterances) that are requests (to the moves of a rival) and those moves that are answers (to the requests) - for an explicit presentation of the rules for standard dialogical logic see appendix 1.

Crucial for the dialogical approach are the following points: ${ }^{13}$

1. The distinction between local (rules for logical constants) and global meaning (included in the structural rules that determine how to play)

2. The player independence of local meaning

3. The distinction between the play level (local winning or winning of a play) and the strategic level (existence of a winning strategy).

4. A notion of validity that amounts to winning strategy independently of any model instead of winning strategy for every model.

5. The distinction between non formal and formal plays - the latter notion concerns plays that are played independently of knowing the meaning of the elementary sentences involved in the main thesis.

In the framework of constructive type theory propositions are sets whose elements are called proof-objects. When such a set is not empty, it can be concluded that the proposition has a proof and that it is true. In his 1988 paper, Ranta proposed a way to make use of this approach in relation to game-theoretical approaches. Ranta took Hintikka's Game Theoretical Semantics as a case study, but the point does not depend on this particular framework. Ranta's idea was that in the context of game-based approaches, a proposition is a set of winning strategies for the player positing the proposition. ${ }^{14}$ Now in game-based approaches, the notion of truth is to be found at the level of such winning strategies. This idea of Ranta's should therefore enable us to apply safely and directly methods taken from constructive type theory to cases of game-based approaches.

But from the perspective of game theoretical approaches, reducing a game to a set of winning strategies is quite unsatisfactory, all the more when it comes to a theory of meaning. This is particularly clear in the dialogical approach in which different levels of meaning are carefully distinguished. There is thus the level of strategies which is a level of meaning analysis, but there is also a level prior to it which is usually called the level of plays. The role of the latter level for developing an analysis is, according to the dialogical approach, crucial, as pointed out by Kuno Lorenz in his 2001 paper:

"[...] for an entity $[A]$ to be a proposition there must exist a dialogue game associated with this entity [...] such that an individual play where A occupies the initial position [...] reaches a final position with either win or loss after a finite number of moves [...]"

For this reason we would rather have propositions interpreted as sets of what we shall call play-objects, reading an expression

\footnotetext{
${ }^{13}$ Cf. Rahman (2012).

${ }^{14}$ That player can be called Player 1, Myself or Proponent.
} 
as " $p$ is a play-object for $\varphi$ ".

$$
p: \varphi
$$

Thus, Ranta's work on proof objects and strategies constitutes the end not the start of the dialogical project.

Before delving into the details about play-objects, let us first discuss the issue of the formation of expressions and in particular of propositions in the context of dialoagical logic.

In standard dialogical systems, there is a presupposition that the players use well-formed formulas. One can check the well formation at will, but only with the usual meta reasoning by which one checks that the formula indeed observes the definition of wff. The first enrichment we want to make is to allow players to question the status of expressions, in particular to question the status of something as actually standing for a proposition. Thus, we start with rules giving a dialogical explanation of the formation of propositions. These are local rules added to the particle rules which give the local meaning of logical constants (see next section).

Let us make a remark before displaying the formation rules. Because the dialogical theory of meaning is based on argumentative interaction, dialogues feature expressions which are not posits of sentences. They also feature requests used for challenges, as illustrated by the formation rules below and the particle rules in the next section. Now, by the no entity without type principle, the type of these actions, which we may write "formation-request", should be specified during a dialogue. Nevertheless we shall consider that the force symbol $?_{F}$ already makes the type explicit. Indeed a request in a dialogue should not be confused with a move by the means of which it is posited that some entity is of the type request. ${ }^{15}$ Hence the way requests are written in rules and dialogues in this work.

\begin{tabular}{|l|l|l|}
\hline Posit & $\begin{array}{l}\text { Challenge } \\
\text { [when different challenges are possible, } \\
\text { the challenger chooses] }\end{array}$ & Defence \\
\hline $\mathbf{Y} ?_{\mathrm{can}} \Gamma$ & $\begin{array}{l}\mathbf{X} ! a_{1}: \Gamma, \mathbf{X} ! a_{2}: \Gamma, \ldots \\
\mathbf{X} \text { gives the canonical } \\
\text { or }\end{array}$ \\
$\mathbf{X} ! \Gamma:$ set & $\mathbf{Y} ?_{\text {gen }} \Gamma$ & $\begin{array}{l}\mathbf{X} ! a_{i}: \Gamma \Rightarrow a_{j}: \Gamma \\
\mathbf{X} \text { provides a generation } \\
\text { method } \\
\mathbf{X} \text { gives the equality rule for } \\
\Gamma^{16}\end{array}$ \\
\hline
\end{tabular}

\footnotetext{
${ }^{15}$ Such a move could be written as ? $\mathrm{Fv} 1$ : formation-request.

${ }^{16}$ See a presentation of equality rules in Appendix 2.
} 


\begin{tabular}{|c|c|c|}
\hline $\mathbf{X} ! \varphi \vee \psi:$ prop & $\begin{array}{l}\mathbf{Y} ?_{\mathrm{Fv} 1} \\
\text { or } \\
\mathbf{Y} ?_{\mathrm{Fv} 2}\end{array}$ & $\begin{array}{l}\mathbf{X} ! \varphi: \text { prop } \\
\text { respectively } \\
\mathbf{X} ! \psi: \text { prop }\end{array}$ \\
\hline $\mathbf{X} ! \varphi \wedge \psi:$ prop & $\begin{array}{l}\mathbf{Y} ?_{\mathrm{F} \wedge 1} \\
\text { or } \\
\mathbf{Y} ?_{\mathrm{F} \wedge 2}\end{array}$ & $\begin{array}{l}\mathbf{X} ! \varphi: \text { prop } \\
\text { respectively } \\
\mathbf{X} ! \psi: \text { prop }\end{array}$ \\
\hline $\mathbf{X} ! \varphi \rightarrow \psi:$ prop & $\begin{array}{l}\mathbf{Y} ?_{\mathrm{F} \rightarrow 1} \\
\text { or } \\
\mathbf{Y} ?_{\mathrm{F} \rightarrow 2} \\
\end{array}$ & $\begin{array}{l}\mathbf{X} ! \varphi: \text { prop } \\
\text { respectively } \\
\mathbf{X} ! \psi: \text { prop }\end{array}$ \\
\hline $\begin{array}{l}\mathbf{X} !(\forall x: A) \varphi(x): \\
\text { prop }\end{array}$ & $\begin{array}{l}\mathbf{Y} ?_{\mathrm{F} \forall 1} \\
\text { or } \\
\mathbf{Y} ?_{\mathrm{F} \forall 2}\end{array}$ & $\begin{array}{l}\mathbf{X} ! A: \text { set } \\
\text { respectively } \\
\mathbf{X} ! \varphi(x): \operatorname{prop}(x: A)\end{array}$ \\
\hline $\begin{array}{l}\mathbf{X} !(\exists x: A) \varphi(x) \text { : } \\
\text { prop }\end{array}$ & $\begin{array}{l}\mathbf{Y} ?_{\mathrm{F} \exists 1} \\
\text { or } \\
\mathbf{Y} ?_{\mathrm{F} \exists 2} \\
\end{array}$ & $\begin{array}{l}\mathbf{X} ! \mathrm{A}: \text { set } \\
\text { respectively } \\
\mathbf{X} ! \varphi(x): \operatorname{prop}(x: A)\end{array}$ \\
\hline $\begin{array}{l}\mathbf{X} ! \mathrm{B}(k) \text { : prop } \\
\text { (for atomic B) }\end{array}$ & $\mathbf{Y} ?_{\mathrm{F}}$ & $\begin{array}{l}\mathbf{X} \operatorname{sic}(n) \\
(\mathbf{X} \text { indicates that } \mathbf{Y} \text { posited it } \\
\text { in move } n)\end{array}$ \\
\hline $\mathbf{X} ! \perp:$ prop & - & - \\
\hline
\end{tabular}

By definition the falsum symbol $\perp$ is of type prop. A posit $\perp$ cannot therefore be challenged.

The next rule is not a formation rule per se but rather a substitution rule. ${ }^{17}$ When $\varphi$ is an elementary sentence, the substitution rule helps explaining the formation of such sentences.

\section{Posit-substitution}

There are two cases in which $\mathbf{Y}$ can ask $\mathbf{X}$ to make a substitution. The first one is when $\mathbf{X}$ has made a posit with a proviso about variables and specified individuals satisfying the proviso: ${ }^{18}$

\begin{tabular}{|l|l|l|}
\hline Posit & Challenge & Defence \\
\hline $\mathbf{X} ! \pi\left(x_{1}, \ldots x_{n}\right)\left(x_{i}: A_{i}\right)$ & $\mathbf{Y} ? x_{1} / \tau_{1}, \ldots, x_{n} / \tau_{n}$ & $\mathbf{X} ! \pi\left(\tau_{1}, \ldots, \tau_{n}\right)$ \\
\hline
\end{tabular}

${ }^{17}$ It is an application of the original rule from CTT given in Ranta (1994 : 30).

${ }^{18}$ See for example move 20 in the example on the donkey sentence below. 
\begin{tabular}{|l|l|l|}
$\mathbf{X} ! \tau_{l}: A_{l}$ & \\
$\cdots$ & & \\
$\mathbf{X} ! \tau_{n}: A_{n}$ & & \\
\hline
\end{tabular}

The second case is when $\mathbf{Y}$ simply grants a substitution of the proviso such that each $x_{i}$ : $A_{i}$ of the proviso has replaced with a term occurring in the posit $\pi\left(x_{1}, \ldots x_{n}\right)-$ as in move 7 of the example below .

\begin{tabular}{|l|l|l|}
\hline Posit & Challenge & Defence \\
\hline $\mathbf{X} ! \pi\left(x_{l}, \ldots x_{n}\right)\left(x_{i}: A_{i}\right)$ & $\mathbf{Y} ! x_{l} / \tau_{1}: \mathrm{A}_{1}, \ldots, x_{1} / \tau_{1}: \mathbf{A}_{n}$ & $\mathbf{X} ! \pi\left(x_{l} / \tau_{1}, \ldots, x_{n} / \tau_{n}\right)$ \\
\hline
\end{tabular}

Remarks on the formation dialogues

(a) Conditional formation posits:

One crucial feature of the formation rules is that they allow displaying the syntactic and semantic presuppositions of a given thesis and thus can be examined by the Opponent before the actual dialogue on the thesis is run. Thus if the thesis amounts to positing, say, $\varphi$, then before an attack is launched, the opponent can asked for its formation. The defence of the formation of $\varphi$, might conduce the Proponent to posit that $\varphi$ is a proposition, under the condition that it is conceded that, say A is a set. In such a situation the Opponent might accept to concede A is a set, but only after P has displayed the constitution of $\mathrm{A}$.

(b) Elementary sentences, definitional consistency and material-analytic dialogues:

If we follow thoroughly the idea of formation rules, one should allow elementary sentences to be challenged: by the formation rules. The defence will make use of the applications of adequate conceded predicator rules (if there are any such concessions). Therefore, what will happen is that the challenge on elementary sentence is based on the definitional consistency in use of the conceded the predicator rules. This is what we think material-dialogues are about: definitional consistency dialogues. This leads to the following material analytic rule for formation dialogues:

O's elementary sentences cannot be challenged, however $\mathbf{O}$ can challenge an elementary sentence (posited by $\mathbf{P}$ ) iff herself (the opponent) did not posit it before.

Remark: Once the proponent forced the Opponent to concede the elementary sentence in the formation dialogue, the dialogue will proceed making use of the copy-cat strategy.

(c) Indoor-versus outdoor-games:

Hintikka (1973: 77-82), who acknowledges the close links between dialogical logic and GTS launched an attack against the philosophical foundations of dialogic because of their indoor- or purely formal approach to meaning as use. He argues that formal proof 
games are not of very much help in accomplishing the task of linking the linguistic rules of meaning with the real world.

In contrast to our games of seeking and finding, the games of Lorenzen and Stegmüller are 'dialogical games' which are played 'indoors' by means of verbal 'challenges' and 'responses'. [...].

[...]. If one is merely interested in suitable technical problems in logic, there may not be much to choose between the two types of games. However, from a philosophical point of view, the difference seems to be absolutely crucial. Only considerations which pertain to 'games of exploring the world' can be hoped to throw any light on the role of our logical concepts in the meaningful use of language. (Hintikka, 1973: 81).

Rahman/Keiff (2005: 379) pointed out that formal proof, that is validity, does not in the dialogical frame provide meaning either: it is rather the other way round, i.e. formal plays furnish the basis for the notion of dialogical validity (that amounts to the notion of a winning $\boldsymbol{P}$-strategy). The formation rules add a crucial edge to this discussion: If the rules that establish meaning are introduced at the object language level the middle position of the dialogical approach between universalists and anti-universalists mentioned above (2.1) can be successfully maintained. ${ }^{19}$ The latter might also thus suggest that the characterization of dialogical games as indoor-games do not apply any more.

By way of illustration, we present a dialogue where the Proponent posits the thesis $(\forall x: A) B(x) \rightarrow C(x)$ : prop given that $A$ : set, $B(x)$ : prop $(x: A)$ and $C(x)$ : prop $(x$ : $A$ ), where the three provisos appear as initial concessions by the Opponent. ${ }^{20}$ Good form demands that we first present the structural rules which define the conditions under which a play can start, proceed and end. But we leave them for the next section. They are not necessary to understand the following:

\begin{tabular}{|l|c|l|l|r|r|}
\hline & O & & & P & \\
\hline I & $! A: \operatorname{set}$ & & & & \\
\hline II & $! B(x): \operatorname{prop}(x: A)$ & & & & \\
\hline III & $! C(x): \operatorname{prop}(x: A)$ & & & & \\
\hline & & & & $!(\forall x: A) B(x) \rightarrow C(x): \operatorname{prop}$ & 0 \\
\hline 1 & $\mathrm{n}:=2$ & & & $\mathrm{~m}:=2$ & 2 \\
\hline 3 & $?_{\mathrm{F} \forall 1}$ & $(0)$ & & $! A: \operatorname{set}$ & 4 \\
\hline 5 & $?_{\mathrm{F} Z 2}$ & $(0)$ & & $! B(x) \rightarrow C(x): \operatorname{prop}(x: A)$ & 6 \\
\hline 7 & $! x: A$ & $(6)$ & & $! B(x) \rightarrow C(x): \operatorname{prop}$ & 8 \\
\hline 9 & $?_{\mathrm{F} \rightarrow 1}$ & $(8)$ & & $B(x): \operatorname{prop}$ & 12 \\
\hline 11 & $! B(x): \operatorname{prop}$ & & $(\mathrm{II})$ & $? x / x$ & 10 \\
\hline
\end{tabular}

${ }_{19}$ Tulenheimo (2011: 111) calls this position the anti-realist anti-universalist position.

${ }^{20}$ The example comes from Ranta $(1994: 31)$. 


\begin{tabular}{|l|c|c|c|c|c|}
13 & $?_{\mathrm{F} \rightarrow 2}$ & $(8)$ & & $! C(x):$ prop & 16 \\
\hline 15 & $! C(x):$ prop & & (III) & $? x / x$ & 14 \\
\hline
\end{tabular}

\section{Explanations:}

- I to III: $\mathbf{O}$ concedes that $A$ is a set and that $B(x)$ and $C(x)$ are propositions provided $x$ is an element of $A$,

- Move 0: $\mathbf{P}$ posits that the main sentence, universally quantified, is a proposition (under the concessions made by $\mathbf{O}$ ),

- Moves 1 and 2: the players choose their repetition ranks,

- Move 3: $\mathbf{O}$ challenges the thesis a first time by asking the left-hand part as specified by the formation rule for universal quantification,

- Move 4: $\mathbf{P}$ responds by positing that $A$ is a set. This has already been granted with the premise I so $\mathbf{P}$ can make this move while respecting the Formal rule,

- Move 5: $\mathbf{O}$ challenges the thesis again, this time asking for the right-hand part, ${ }^{21}$

- Move 6: $\mathbf{P}$ responds, positing that $B(x) \rightarrow C(x)$ is a proposition provided $x: A$,

- Move 7: $\mathbf{O}$ uses the substitution rule to challenge move 6 by granting the proviso,

- Move 8: $\mathbf{P}$ responds by positing that $B(x) \rightarrow C(x)$ is a proposition,

- Move 9: $\mathbf{O}$ then challenges move 8 a first time by asking the left-hand part as specified by the formation rule for material implication.

In order to defend $\mathbf{P}$ needs to make an elementary move. But since $\mathbf{O}$ has not played it yet, $\mathbf{P}$ cannot defend at this point. Thus:

- Move 10: $\mathbf{P}$ launches a counterattack against assumption II by applying the first case of the substitution rule,

- Move 11: $\mathbf{O}$ answers move 10 and posits that $B(x)$ is a proposition,

- Move 12: $\mathbf{P}$ can now defend in reaction to move 9,

- Move 13: $\mathbf{O}$ challenges move 8 a second time, this time requiring the right-hand part of the conditional,

- Move 14: P launches a counterattack and challenges assumption III by applying again the first case of the substitution rule

- Move 15: $\mathbf{O}$ defends by positing that $C(x)$ is a proposition,

- Move 16: $\mathbf{P}$ can now answer to the request of move 13 and win the dialogue ( $\mathbf{O}$ has no further move).

From the view point of building a winning strategy, the Proponent's victory only shows that the thesis is justified in this particular play. To build a winning strategy we must run all the relevant plays for this thesis under these concessions.

Now that the dialogical account of formation rules has been clarified, we may develop further our analysis of plays by introducing play-objects.

\section{LOCAL MEANING II: PLAY OBJECTS}

The idea is now to design dialogical games in which the players' posits are of the form " $p: \varphi$ " and acquire their meaning in the way they are used in the game - i.e., how they

\footnotetext{
${ }^{21}$ This can be done because $\mathbf{O}$ has chosen 2 for her repetition rank.
} 
are challenged and defended. This requires, among others, to analyse the form of a given play-object $p$, which depends on $\varphi$, and how a play-object can be obtained from other, simpler, play-objects. The standard dialogical semantics ${ }^{22}$ for logical constants gives us the needed information for this purpose. The main logical constant of the expression at stake provides the basic information as to what a play-object for that expression consists of:

A play for $\mathbf{X} ! \varphi \vee \psi$ is obtained from two plays $p_{1}$ and $p_{2}$, where $p_{1}$ is a play for $\mathbf{X} ! \varphi$ and $p_{2}$ is a play for $\mathbf{X} ! \psi$. According to the particle rule for disjunction, it is the player $\mathbf{X}$ who can switch from $p_{1}$ to $p_{2}$ and vice-versa. To show this, we write that the play is of the form $\left(p_{1}+p_{2}\right)$.

A play for $\mathbf{X} ! \varphi \wedge \psi$ is obtained similarly, except that it is the player $\mathbf{Y}$ who can switch from $p_{1}$ to $p_{2}$. To show this, we write that the play is of the form $\left(p_{1} \otimes p_{2}\right)$.

A play for $\mathbf{X} ! \varphi \rightarrow \psi$ is obtained from two plays $p_{1}$ and $p_{2}$, where $p_{1}$ is a play for $\mathbf{Y} ! \varphi$ and $p_{2}$ is a play for $\mathbf{X} ! \psi$. It is the player $\mathbf{X}$ who can switch from $p_{1}$ to $p_{2}$. We write that the play is of the form $\left(p_{1}-\mathrm{O} p_{2}\right)$.

The standard dialogical particle rule for negation rests on the interpretation of $\neg \varphi$ as an abbreviation for $\varphi \rightarrow \perp$, although it is usually left implicit. It follows that a play for $\mathbf{X} ! \neg \varphi$ is also of the form $\left(p_{1}-\mathrm{o} p_{2}\right)$, where $p_{1}$ is a play for $\mathbf{Y} ! \varphi$ and $p_{2}$ is a play for $\mathbf{X} ! \perp$, and where $\mathbf{X}$ can switch from $p_{1}$ to $p_{2}$. Notice that this approach covers the standard game-theoretical interpretation of negation as role-switch: $p_{1}$ is a play for a $\mathbf{Y}$ move.

As for quantifiers, we give a detailed discussion after the particle rules (see next page). ${ }^{23}$ For now, we would like to point out that, just like what is done in constructive type theory, we are dealing with quantifiers for which the type of the bound variable is always specified. We thus consider expressions of the form $(\mathrm{Q} x: A) \varphi$, where $\mathrm{Q}$ is a quantifier symbol.

It may seem unfortunate that we use symbols that are usually used to denote linear connectives $(\otimes,-0)$. We use these because their game-theoretical interpretations ${ }^{24}$ completely match the descriptions we have just given of how play-objects can be obtained from simpler ones.

\begin{tabular}{|l|l|l|}
\hline Posit & Challenge & Defence \\
\hline $\begin{array}{l}\mathbf{X} ! \varphi \\
\text { (where no play-object has been specified for } \varphi)\end{array}$ & Y ? play-object & $\mathbf{X} ! p: \varphi$ \\
\hline
\end{tabular}

\footnotetext{
22 See Appendix 1.

23 A similar comment to the one we made for formation-requests on p.3 can be made here.

24 See for example Blass(1992).
} 


\begin{tabular}{|c|c|c|}
\hline \multirow[b]{2}{*}{$\begin{array}{l}\mathbf{X} ! p: \varphi \vee \psi \\
\text { Description of } p:(p I+p 2)\end{array}$} & $\mathbf{Y}$ ?prop & $\mathbf{X} ! \varphi \vee \psi$ : prop \\
\hline & $\mathbf{Y} ?[\varphi, \psi]$ & $\begin{array}{l}\mathbf{X} ! \mathrm{L}(p): \varphi \\
\text { Or } \\
\mathbf{X} ! R(p): \psi \\
\text { [the defender has the choice] }\end{array}$ \\
\hline \multirow[b]{4}{*}{$\begin{array}{l}\mathbf{X} ! p: \varphi \rightarrow \psi \\
\text { Description of } p:(p l-\mathrm{o} p 2) .\end{array}$} & $\mathbf{Y}$ ?prop & $\mathbf{X} ! \varphi \wedge \psi$ : prop \\
\hline & $\begin{array}{l}\mathbf{Y} ?[\varphi] \\
\text { or } \\
\mathbf{Y} ?[\psi] \\
\text { [the challenger has the choice] }\end{array}$ & $\begin{array}{l}\mathbf{X} ! \mathrm{L}(p): \varphi \\
\text { respectively } \\
\mathbf{X} ! \mathrm{R}(p): \psi\end{array}$ \\
\hline & $\mathbf{Y}$ ?prop & $\mathbf{X} ! \varphi \rightarrow \psi$ : prop \\
\hline & $\mathbf{Y} ! \mathrm{L}(p): \varphi$ & $\mathbf{X} ! \mathrm{R}(p): \psi$ \\
\hline \multirow[b]{2}{*}{$\begin{array}{l}\mathbf{X} ! p: \neg \varphi \\
\text { Description of } p:(p l-\mathrm{o} \perp) .\end{array}$} & $\mathbf{Y}$ ?prop & $\mathbf{X} ! \neg \varphi$ : prop \\
\hline & $\mathbf{Y} ! \mathrm{L}(p): \varphi$ & $\mathbf{X} ! \mathrm{R}(p): \perp$ \\
\hline \multirow[b]{2}{*}{$\begin{array}{l}\mathbf{X} ! p:(\exists x: A) \varphi \\
\text { Description of } p:(p 1 \otimes p 2) .\end{array}$} & $\mathbf{Y}$ ?prop & $\mathbf{X} !(\exists x: A) \varphi$ : prop \\
\hline & $\begin{array}{l}\mathbf{Y} \text { ?L } \\
\text { or } \\
\mathbf{Y} \text { ?R } \\
\text { [the challenger has the choice] }\end{array}$ & $\begin{array}{l}\mathbf{X} ! \mathrm{L}(p): A \\
\text { respectively } \\
\mathbf{X} ! \mathrm{R}(p): \varphi(\mathrm{L}(p))\end{array}$ \\
\hline $\begin{array}{l}\mathbf{X} ! p:\{x: A \mid \varphi\} \\
\text { Description of } p:(p 1 \otimes p 2) \text {. }\end{array}$ & $\begin{array}{l}\mathbf{Y} \text { ?L } \\
\text { or } \\
\mathbf{Y} \text { ?R } \\
\text { [the challenger has the choice] }\end{array}$ & $\begin{array}{l}\mathbf{X} ! \mathrm{L}(p): A \\
\text { respectively } \\
\mathbf{X} ! \mathrm{R}(p): \varphi(\mathrm{L}(p))\end{array}$ \\
\hline \multirow[b]{2}{*}{$\begin{array}{l}\mathbf{X} ! p:(\forall x: A) \varphi \\
\text { Description of } p:(p 1-\mathrm{o} p 2) .\end{array}$} & $\mathbf{Y}$ ?prop & $\mathbf{X} !(\forall x: A) \varphi:$ prop \\
\hline & $\mathbf{Y} \mathrm{L}(p): A$ & $\mathbf{X} ! \mathrm{R}(p): \varphi(\mathrm{L}(p))$ \\
\hline \multirow[b]{2}{*}{$\begin{array}{l}\mathbf{X} ! p: \mathrm{B}(k) \\
\text { (for atomic } \mathrm{B} \text { ) }\end{array}$} & $\mathbf{Y}$ ?prop & $\mathbf{X} ! \mathrm{B}(k)$ : prop \\
\hline & $\mathbf{Y} ?$ & $\begin{array}{l}\mathbf{X} ! \operatorname{sic}(n) \\
(\mathrm{X} \text { indicates that } \mathrm{Y} \text { posited it at move } n)\end{array}$ \\
\hline
\end{tabular}

Notice that we have added for each logical constant a challenge of the form ' $\mathbf{Y}$ ?prop' by which the challenger questions the fact that the expression at the right-hand side of the semi-colon is a proposition. This makes the connection with the formation rules given in 3.1 via X's defence. More details are given in the discussion after the structural rules. 
It may happen, as we shall see in our example in Section 2, that the form of play-objects is not explicit at first. In such cases we deal with expressions of the form, e.g., " $p: \varphi \wedge \psi$ ". We may then use expressions of the form $\mathrm{L}(p)$ and $\mathrm{R}(p)-$ which we call instructions - in the relevant defences. Their respective interpretations are "take the left part of $p$ " and "take the right part of $p$ ".

Let us focus on the rules for quantifiers. Dialogical semantics highlights the fact that there are two distinct moments when considering the meaning of quantifiers: the choice of a value given to the bound variable, and the instantiation of the formula after replacing the bound variable with the chosen value. But at the same time in the standard dialogical approach there is some sort of presupposition that every quantifier symbol ranges on a unique kind of objects. Now, things are different in the context of the explicit language we borrow from CTT. Quantification is always relative to a set, and there are sets of many different kinds of objects (for example: sets of individuals, sets of pairs, sets of functions, etc). Thanks to the instructions we can give a general form for the particle rules. It is in a third, later, moment that the kind of object is specified, when instructions are "resolved" by means of the structural rule SR4.1 below.

Constructive type theory makes it clear that as soon as propositions are thought of as sets, there is a basic similarity between conjunction and existential quantifier on the one hand and material implication and universal quantifier on the other hand. Briefly, the point is that they are formed in similar ways and their elements are generated by the same kind of operations. ${ }^{25}$ In our approach, this similarity manifests itself in the fact that a play-object for an existentially quantified expression is of the same form as a play-object for a conjunction. Similarly, a play-object for a universally quantified expression is of the same form as one for a material implication. ${ }^{26}$

The particle rule following the one for universal quantification is a novelty in the dialogical approach. It involves expressions commonly used in constructive type theory to deal with separated subsets. The idea is to understand those elements of $A$ such that $\varphi$ as expressing that at least one element $\mathrm{L}(p)$ of $A$ witnesses $\varphi(\mathrm{L}(p))$. The same correspondence that linked conjunction and existential quantification now appears. ${ }^{27}$ This is not surprising since such posits actually have an existential aspect: in $\{x$ $: A \mid \varphi\}$ the left part " $x: A$ " signals the existence of a play-object. ${ }^{28}$

\footnotetext{
${ }^{25}$ More precisely, conjunction and existential quantifier are two particular cases of the $\Sigma$ operator (disjoint union of sets), whereas material implication and universal quantifier are two particular cases of the $\Pi$ operator (indexed product on sets). See for example Ranta (1994), Chapter 2.

${ }^{26}$ Still, if we are playing with structural rules, there is a slight difference between material implication and universal quantification which we take from Ranta (1994, Table 2.3), namely that in the second case $\mathrm{p}_{2}$ always depends on $\mathrm{p}_{1}$.

${ }^{27}$ As pointed out in Martin-Löf (1984), subset separation is another case of the $\Sigma$ operator. See in particular p. 53:

"Let $\mathrm{A}$ be a set and $\mathrm{B}(\mathrm{x})$ a proposition for $\mathrm{x} \varepsilon \mathrm{A}$. We want to define the set of all a $\varepsilon \mathrm{A}$ such that $\mathrm{B}(\mathrm{a})$ holds (which is usually written $\{x \in A: B(x)\})$. To have an element a $\varepsilon A$ such that $B(a)$ holds means to have an element $a \varepsilon A$ together with a proof of $B(a)$, namely an element $b \varepsilon B(a)$. So the elements of the set of all elements of $\mathrm{A}$ satisfying $\mathrm{B}(\mathrm{x})$ are pairs $(\mathrm{a} ; \mathrm{b})$ with $\mathrm{b} \varepsilon \mathrm{B}(\mathrm{a})$, i.e. elements of $(\Sigma \mathrm{x} \varepsilon \mathrm{A}) \mathrm{B}(\mathrm{x})$. Then the $\Sigma$-rules play the role of the comprehension axiom (or the separation principle in ZF)."

${ }^{28}$ The link between subset-separation and existentials provides an insight in the much discussed understanding of the comprehension principle of the Erlanger Constructivists, who proposed to develop a constructivist abstraction process from predicator rules to universal quantification - see Lorenzen (1962), (Lo-
} 
Let us point out that since the expression stands for a set it cannot be challenged with the request "? prop". However, the formation of the set could be challenged and then we are at the start of our paper again: the grounding of the elementary sentences.

Let us now introduce the other kind of dialogical rules called structural rules. These rules govern the way plays globally proceed and are therefore an important aspect of a dialogical semantics.

\section{GLOBAL MEANING}

SR0 (Starting rule) Any dialogue starts with the Proponent positing the thesis. After that the players each choose a positive integer called repetition ranks.

SR1i (Intuitionistic Development rule) Players move alternately. After the repetition ranks have been chosen, each move is a challenge or a defence in reaction to a previous move, in accordance with the particle rules. The repetition rank of a player bounds the number of challenges he can play in reaction to a same move. Players can answer only against the last non-answered challenge by the adversary.

[SR1c (Classical Development rule) Players move alternately. After the repetition ranks have been chosen, each move is a challenge or a defence in reaction to a previous move, in accordance with the particle rules. The repetition rank of a player bounds the number of challenges and defences he can play in reaction to a same move.]

SR2 (Formation first) $O$ starts by challenging the thesis with the request '? ${ }_{\text {prop }}$. The game then proceeds by applying the formation rules first in order to check that the thesis is indeed a proposition. After that the Opponent is free to use the other local rules insofar as the other structural rules allow it.

SR3 (Modified Formal rule) O's elementary sentences cannot be challenged, however $\mathbf{O}$ can challenge an elementary sentence (posited by $\mathbf{P}$ ) iff herself (the opponent) did not posit it before.

SR4.1 (Resolution of instructions) Whenever a player posits a move where instructions $I_{1}, \ldots, I_{n}$ occur, the other player can ask him to replace these instructions (or some of them) by their values. The corresponding defence is to posit the result of the substitution:

\begin{tabular}{|l|l|l|}
\hline Posit & Challenge & Defence \\
\hline $\mathbf{X} ! \pi\left(I_{1}, \ldots, I_{n}\right)$ & $\mathbf{Y} I_{l}, \ldots, I_{m}=? \quad(\mathrm{~m} \leq \mathrm{n})$ & $\mathbf{X} ! \pi\left(b_{l}, \ldots, b_{m}\right)$ \\
\hline
\end{tabular}

renzen/Schwemmer (1975: 194-202) and Siegwart (1993). Martin-Löf's approach delivers the right keys: a) Instead of predicator transitions, the conjugation between a propositional function and the corresponding set is necessary b) the resulting principle has an existential not a universal form. 
\begin{tabular}{|l|l|l|}
\hline & (The defender chooses $)$ \\
\hline
\end{tabular}

Important remark. In the case of embedded instructions $\mathrm{I}_{1}\left(\ldots\left(\mathrm{I}_{\mathrm{k}}\right) \ldots\right)$, the substitutions are thought as being carried out from $\mathrm{I}_{\mathrm{k}}$ to $\mathrm{I}_{1}$ : first substitute $\mathrm{I}_{\mathrm{k}}$ with some value $b_{\mathrm{k}}$, then $\mathrm{I}_{\mathrm{k} \text { - }}$ ${ }_{1}\left(b_{\mathrm{k}}\right)$ with $\mathrm{b}_{\mathrm{k}-1} \ldots$ until $\mathrm{I}_{1}\left(b_{2}\right)$. If such a progressive substitution has actually been carried out once, a player can then replace $\mathrm{I}_{1}\left(\ldots\left(\mathrm{I}_{\mathrm{k}}\right) \ldots\right)$ directly. ${ }^{29}$

SR4.2 (Substitution of instructions) Whenever a player $\mathbf{X}$ has chosen a value $b$ for an instruction I, the antagonist can ask to substitute I with $b$ in any posit $\mathbf{X} ! \pi(\mathrm{I})$ :

\begin{tabular}{|l|l|l|}
\hline Posit & Challenge & Defence \\
\hline $\mathbf{X} ! \pi_{i}(I)$ & & \\
$\mathbf{Y} I=?$ & & \\
$\mathbf{X} ! \pi_{i}(b)$ & & \\
$\cdots$ & & $\mathbf{X} ! \pi_{j}(b)$ \\
$\mathbf{X}-!-\pi_{j}(I)$ & $\mathbf{Y} ? I / b$ & \\
\hline
\end{tabular}

SR5 (Winning rule for dialogues) For any $p$, a player who posits " $p: \perp$ " looses the current dialogue. Otherwise the player who makes the last move in a dialogue wins it.

A detailed explanation of the standard rules can be found in Appendix 1. In the rules we just gave there are some additions, namely those numbered SR2 and SR4 here, and also the first part of the winning rule. Since we made explicit the use of $\perp$ in our games, we need to add a rule for it: the point is that positing falsum leads to immediate loss; we could say that it amounts to a withdrawal. ${ }^{30}$

We need the rules SR4.1 and SR4.2 because of some features of CTT's explicit language. In CTT it is possible to account for questions of dependency, scope, and so on, directly at the level of the language. In this way various puzzles, such as anaphora, get a convincing and successful treatment. The typical example, which we consider below, is the so-called donkey sentence "Every man who owns a donkey beats it". The two rules give a mean to account for the way values can be ascribed to what we have called instructions. See the dialogue below for an application.

Let us take an example for the development of a dialogue the case of the notorious donkey sentence. In his 1986 paper, G. Sundholm thoroughly discussed this famous puzzle. As he pointed out, the problem is to give a way to capture the backreference of the pronoun "it" in the sentence "Every man who owns a donkey beats it". For that we first notice that "a man who owns a donkey" is an element of the set

$$
\{x: M \mid(\exists y: D) \mathrm{O} x y\},
$$

\footnotetext{
${ }^{29}$ See for example move 22 in the example below.

${ }^{30}$ See Keiff (2007).
} 
making use of subset separation. From there it is easy to use projections to get the following formula for the donkey sentence:

$$
(\forall z:\{x: M \mid(\exists y: D) \mathrm{O} x y\}) \mathrm{B}(\mathrm{L}(z), \mathrm{L}(\mathrm{R}(z)))
$$

where $M$ is the set of men, $D$ is the set of donkeys, Oxy stands for " $x$ owns $y$ " and Bxy stands for " $x$ beats $y$ ". In this way we account for the fact that the pronoun "it" refers to the donkey mentioned in the first part of the sentence.

Consider the following dialogue for the donkey sentence, with a preliminary concession by the Opponent:

\begin{tabular}{|c|c|c|c|c|c|}
\hline & $\mathbf{O}$ & & & $\mathbf{P}$ & \\
\hline \multirow[t]{2}{*}{ I } & $! B(x, y)(x: M, y: D)$ & & & & \\
\hline & & & & $\begin{array}{c}! p:(\forall z:\{x: M \mid(\exists y: D) O x y\}) \\
B(L(z), L(R(z)))\end{array}$ & 0 \\
\hline 1 & $\mathrm{n}:=1$ & & & $\mathrm{~m}:=2$ & 2 \\
\hline 3 & $! \mathrm{L}(p):\{x: M \mid(\exists y: D) O x y\}$ & (0) & & $! R(p): B(\mathrm{~L}(\mathrm{~L}(p)), L(R(\mathrm{~L}(p))))$ & 4 \\
\hline 5 & $\mathrm{~L}(\mathrm{~L}(p)), \mathrm{L}(R(\mathrm{~L}(p)))=?$ & (4) & & $! R(p): B(m, d)$ & 22 \\
\hline 7 & $! \mathrm{L}(\mathrm{L}(p)): M$ & & (3) & $?_{L}$ & 6 \\
\hline 9 & $! m: M$ & & (7) & $\mathrm{L}(\mathrm{L}(p))=?$ & 8 \\
\hline 11 & $! \mathrm{R}(\mathrm{L}(p)):(\exists y: D) O L(a) y$ & & (3) & $?_{R}$ & 10 \\
\hline 13 & $! \mathrm{L}(\mathrm{R}(\mathrm{L}(p))): D$ & & (11) & $?_{L}$ & 12 \\
\hline 15 & $! \mathrm{R}(\mathrm{R}(\mathrm{L}(p))): O \mathrm{~L}(\mathrm{~L}(p)) \mathrm{L}(\mathrm{R}(\mathrm{L}(p)))$ & & (9) & $?_{R}$ & 14 \\
\hline 17 & $\mathrm{R}(\mathrm{R}(\mathrm{L}(p))): O m \mathrm{~L}(\mathrm{R}(\mathrm{L}(p)))$ & & (15) & $? \mathrm{~L}(\mathrm{~L}(p)) / m$ & 16 \\
\hline 19 & $\mathrm{R}(\mathrm{R}(\mathrm{L}(p))): O m d$ & & (15) & $\mathrm{L}(\mathrm{R}(\mathrm{L}(p)))=?$ & 18 \\
\hline 21 & $! B(m, d)$ & & (I) & $? m: M, d: D$ & 20 \\
\hline 23 & $\mathrm{R}(p)=?$ & (4) & & $! q: B(m, d)$ & 26 \\
\hline 25 & $! q: B(m, d)$ & (16) & $(21)$ & ? play-object & 24 \\
\hline
\end{tabular}

Explanations. With move 3 the Opponent uses the particle rule for universal quantification and challenges the thesis. The Proponent defends himself and the Opponent then challenges move 4 in accordance with the rule for resolution of instructions. In order to defend himself, the Proponent needs to choose values for the instructions $\mathrm{L}(\mathrm{L}(p))$ and $\mathrm{LR}(\mathrm{L}(p))$. He thus counterattacks, starting with move 6 . In this way he makes the Opponent choose values for these instructions at moves 9 and $19-$ which respectively are $m$ and $d$. In accordance to the remark we made in rule SR4.1, the Proponent then chooses these values for his move 22. When the Opponent asks for the value of $\mathrm{R}(p)$ at move 23, the Proponent can challenge $\mathbf{O}$ 's concession and choose the same $q$ used by $\mathbf{O}$ for his own defence at move 26 .

We reached herewith the end of our presentation. For sure, there is a big work still ahead, but it is a fascinating one. The dynamic turn initiated by dialogical logic has 
shown to be fruitful in many fields. The time is ripe to explore the possibilities of linking the approach of dialogical logic on one hand to a general theory of meaning.

\section{Appendix 1: Standard Dialogical Logic}

Let $L$ be a first-order language built as usual upon the propositional connectives, the quantifiers, a denumerable set of individual variables, a denumerable set of individual constants and a denumerable set of predicate symbols (each with a fixed arity).

We extend the language $L$ with two labels $\mathbf{O}$ and $\mathbf{P}$, standing for the players of the game, and the question mark '?'. When the identity of the player does not matter, we use variables $\mathbf{X}$ or $\mathbf{Y}$ (with $\mathbf{X} \neq \mathbf{Y}$ ). A move is an expression of the form ' $\mathbf{X}-e^{\prime}$, where $e$ is either a formula $\varphi$ of $L$ or the form '? $\left[\varphi_{1}, \ldots, \varphi_{n}\right]$ '.

We now present the rules of dialogical games. There are two distinct kinds of rules named particle (or local) rules and structural rules. We start with the particle rules.

\begin{tabular}{|c|c|c|c|c|}
\hline Previous move & $\mathbf{X}-\varphi \wedge \psi$ & $\mathbf{X}-\varphi \vee \psi$ & $\mathbf{X}-\varphi \rightarrow \psi$ & $\mathbf{X}-\neg \varphi$ \\
\hline Challenge & $\begin{array}{c}\mathbf{Y}-?[\varphi] \text { or } \\
\mathbf{Y}-?[\psi]\end{array}$ & $\mathbf{Y}-?[\varphi, \psi]$ & $\mathbf{Y}-\varphi$ & $\mathbf{Y}-\varphi$ \\
\hline Defence & $\begin{array}{c}\mathbf{X}-\varphi \\
\text { resp. } \mathbf{X}-\psi\end{array}$ & $\begin{array}{c}\mathbf{X}-\varphi \\
\text { or } \mathbf{X}-\psi\end{array}$ & $\mathbf{X}-\psi$ & -- \\
\hline
\end{tabular}

\begin{tabular}{|c|c|c|}
\hline Previous move & $\mathbf{X}-\forall \mathrm{x} \varphi$ & $\mathbf{X}-\exists \mathrm{x} \varphi$ \\
\hline Challenge & $\mathbf{Y}-?[\varphi(\mathrm{a} / \mathrm{x})]$ & $\mathbf{Y}-?\left[\varphi\left(\mathrm{a}_{1} / \mathrm{x}\right), \ldots, \varphi\left(\mathrm{a}_{\mathrm{n}} / \mathrm{x}\right)\right]$ \\
\hline Defence & $\mathbf{X}-\varphi(\mathrm{a} / \mathrm{x})$ & $\begin{array}{c}\mathbf{X}-\varphi\left(\mathrm{a}_{\mathrm{i}} / \mathrm{x}\right) \\
\text { with } 1 \leq \mathrm{i} \leq \mathrm{n}\end{array}$ \\
\hline
\end{tabular}

In this table, the $\mathrm{a}_{\mathrm{i}} \mathrm{s}$ are individual constants and $\varphi\left(\mathrm{a}_{\mathrm{i}} / \mathrm{x}\right)$ denotes the formula obtained by replacing every occurrence of $x$ in $\varphi$ by $a_{i}$. When a move consists in a question of the form '? $\left[\varphi_{1}, \ldots, \varphi_{n}\right]$ ', the other player chooses one formula among $\varphi_{1}, \ldots, \varphi_{n}$ and plays it. We can thus distinguish between conjunction and disjunction on the one hand, and universal and existential quantification on the other hand, in terms of which player has a choice. In the cases of conjunction and universal quantification, the challenger chooses which formula he asks for. Conversely, in the cases of disjunction and existential quantification, the defender is the one who can choose between various formulas. Notice that there is no defence in the particle rule for negation.

Particle rules provide an abstract description of how the game can proceed locally: they specify the way a formula can be challenged and defended according to its main logical constant. In this way we say that these rules govern the local level of meaning. Strictly speaking, the expressions occurring in the table above are not actual moves because they feature formulas schemata and the players are not specified. Moreover, these rules are indifferent to any particular situations that might occur during the 
game. For these reasons we say that the description provided by the particle rules is abstract.

Since the players' identities are not specified in these rules, we say that particle rules are symmetric: that is, the rules are the same for the two players. The fact that the local meaning is symmetric (in this sense) is one of the biggest strengths of the dialogical approach to meaning. In particular it is the reason why the dialogical approach is immune to a wide range of trivializing connectives such as Prior's tonk. ${ }^{31}$

The expressions occurring in particle rules are all move schematas. The words "challenge" and "defence" are convenient to name certain moves according to their relationship with other moves. Such relationships can be precisely defined in the following way. Let $\Sigma$ be a sequence of moves. The function $p_{\Sigma}$ assigns a position to each move in $\Sigma$, starting with 0 . The function $F_{\Sigma}$ assigns a pair $[m, Z]$ to certain moves $N$ in $\Sigma$, where $m$ denotes a position smaller than $p_{\Sigma}(N)$ and $Z$ is either $C$ or $D$, standing respectively for "challenge" and "defence". That is, the function $F_{\Sigma}$ keeps track of the relations of challenge and defence as they are given by the particle rules. Consider for example the following sequence $\Sigma$ :

$$
\mathbf{P}-\varphi \wedge \psi, \mathbf{P}-\chi \vee \psi, \mathbf{O}-?[\varphi], \mathbf{P}-\varphi
$$

In this sequence we have for example $p_{\Sigma}(\mathbf{P}-\chi \vee \psi)=1$.

A play (or dialogue) is a legal sequence of moves, i.e., a sequence of moves which observes the game rules. The rules of the second kind that we mentioned, the structural rules, give the precise conditions under which a given sentence is a play. The dialogical game for $\varphi$, written $\mathrm{D}(\varphi)$, is the set of all plays with $\varphi$ as the thesis (see the Starting rule below). The structural rules are the following:

SR0 (Starting rule) Let $\varphi$ be a complex formula of L. For every $\pi \in \mathrm{D}(\varphi)$ we have:

- $\quad p_{\pi}(\mathbf{P}-\varphi)=0$,

- $p_{\pi}(\mathbf{O}-\mathrm{n}:=i)=1$,

- $\quad p_{\pi}(\mathbf{P}-\mathrm{m}:=j)=2$

In other words, any play $\pi$ in $D(\varphi)$ starts with $\mathbf{P}-\varphi$. We call $\varphi$ the thesis of the play and of the dialogical game. After that, the Opponent and the Proponent successively choose a positive integer called repetition rank. The role of these integers is to ensure that every play ends after finitely many moves, in a way specified by the next structural rule.

\section{SR1 (Classical game-playing rule)}

- Let $\pi \in \mathrm{D}(\varphi)$. For every $M$ in $\pi$ with $p_{\pi}(M)>2$ we have $F_{\pi}(M)=\left[m^{\prime}, Z\right]$ with $m^{\prime}<p_{\pi}(M)$ and $Z \in\{C, D\}$

\footnotetext{
${ }^{31}$ See Rahman et al. (2009) and Rahman (2012).
} 
- Let $r$ be the repetition rank of player $\mathbf{X}$ and $\pi \in \mathrm{D}(\varphi)$ such that

- the last member of $\pi$ is a $\mathbf{Y}$ move,

- $M_{0}$ is a $\mathbf{Y}$ move of position $m_{0}$ in $\pi$,

- $M_{1}, \ldots, M_{\mathrm{n}}$ are $\mathbf{X}$ moves in $\pi$ such that $F_{\pi}\left(M_{1}\right)=\ldots=F_{\pi}\left(M_{\mathrm{n}}\right)=\left[m_{0}, Z\right]$.

Consider the sequence ${ }^{32} \pi^{\prime}=\pi * N$ where $N$ is an $\mathbf{X}$ move such that

$\mathrm{F}_{\pi^{\prime}}(N)=\left[m_{0}, Z\right]$. We have $\pi^{\prime} \in \mathrm{D}(\varphi)$ only if $\mathrm{n}<r$.

The first part of the rule states that every move after the choice of repetition ranks is either a challenge or a defence. The second part ensures finiteness of plays by setting the player's repetition rank as the maximum number of times he can challenge or defend against a given move of the other player.

SR2 (Formal rule) Let $\psi$ be an elementary sentence, $N$ be the move $\mathbf{P}-\psi$ and $M$ be the move $\mathbf{O}-\psi$. A sequence $\pi$ of moves is a play only if we have: if $N \in \pi$ then $M \in \pi$ and $p_{\pi}(M)<p_{\pi}(N)$.

That is, the Proponent can play an elementary sentence only if the Opponent played it previously. The formal rule is one of the characteristic features of the dialogical approach: other game-based approaches do not have it (see comments below).

One way to understand the formal rule is that it establishes a kind of game where one of the players must play without knowing meaning of the elementary sentences involved.. Now, if the ultimate grounds of a dialogical thesis are elementary sentences and if this is implemented by the use of a formal rule, then the dialogues are in this sense necessarily asymmetric. Indeed, if both contenders were restricted by the formal rule no elementary sentence can ever be posited. Thus, we implement the formal rule by designing one player, called the proponent, whose declarative utterances of elementary sentences are at least, at the start of the dialogue, restricted by this rule. Moreover the formal rule triggers a novel notion of validity. Validity is not being understood as being true in every model, but as having a winning strategy independently of any model or more generally independently of any material grounding claim (such as truth or justification). The copy-cat strategy implicit in the formal rule is not copy-cat of groundings but copy-cat of declarative utterances involving elementary sentences. ${ }^{33}$ The copy-cat of groundings or contents corresponds rather to the modified formal rule for material analytic dialogues discussed in Section 3.2 of the present paper. ${ }^{34}$

A play is called terminal when it cannot be extended by further moves in compliance with the rules. We say it is $\mathbf{X}$ terminal when the last move in the play is an $\mathbf{X}$ move.

SR3 (Winning rule) Player $\mathbf{X}$ wins the play $\pi$ only if it is $\mathbf{X}$ terminal.

\footnotetext{
${ }^{32}$ We use $\pi * N$ to denote the sequence obtained by adding move $N$ to the play $\pi$.

33 This has been pointed out by Helge Rückert $(2011 \mathrm{~b})$ at the workshop Proofs and Dialogues, Tübingen, Wilehm-Schickard Institut für Informatik. See also Rückert (2001) for more discussion on the formal rule.

${ }^{34}$ Although Marion and Rückert (2012) suggest that the use of the dialogical formal rule is already present in Aristotle - and perhaps even in Plato -, it seems to us that it is in fact the modified one we formulated in Section 3.2 for the material-analytic dialogues.
} 
Consider for example the following sequences of moves:

$$
\begin{aligned}
& \mathbf{P}-\mathrm{Qa} \wedge \mathrm{Qb}, \mathbf{O}-\mathrm{n}:=1, \mathbf{P}-\mathrm{m}:=6, \mathbf{O}-\text { ? [Qa], P-Qa } \\
& \mathbf{P}-\mathrm{Q} a \rightarrow \mathrm{Q} a, \mathbf{O}-\mathrm{n}:=1, \mathbf{P}-\mathrm{m}:=12, \mathbf{O}-\mathrm{Q} \text {, P-Qa }
\end{aligned}
$$

The first one is not a play because it contravenes the Formal rule: with his last move, the Proponent plays an atomic sentence although the Opponent did not play it beforehand. By contrast, the second sequence is a play in $\mathrm{D}(\mathbf{P}-\mathbf{Q} \rightarrow \mathbf{Q a})$. We often use a convenient table notation for plays. For example, we can write this play as follows:

\begin{tabular}{|l|c|l|l|c|r|}
\hline & O & & & P & \\
\hline & & & & $\mathrm{Qa} \rightarrow \mathrm{Qa}$ & 0 \\
\hline 1 & $\mathrm{n}:=1$ & & & $\mathrm{~m}:=12$ & 2 \\
\hline 3 & $\mathrm{Qa}$ & $(0)$ & & $\mathrm{Qa}$ & 4 \\
\hline
\end{tabular}

The numbers in the external columns are the positions of the moves in the play. When a move is a challenge, the position of the challenged move is indicated in the internal columns, as with move 3 in this example. Notice that such tables carry the information given by the functions $p$ and $F$ in addition to represent the play itself.

However, when we want to consider several plays together - or example when building a strategy - such tables are not that perspicuous. So we do not use them to deal with dialogical games for which we prefer another perspective. The extensive form of the dialogical game $D(\varphi)$ is simply the tree representation of it, also often called the game-tree. More precisely, the extensive form $\mathrm{E}_{\varphi}$ of $\mathrm{D}(\varphi)$ is the tree $(T, l, S)$ such that:

i) Every node $t$ in $T$ is labelled with a move occurring in $\mathrm{D}(\varphi)$

ii) $f: T \rightarrow \mathrm{N}$

iii) $S \subseteq T^{2}$ with:

- There is a unique $t_{0}$ (the root) in $T$ such that $\ell\left(t_{0}\right)=0$, and $t_{0}$ is labelled with the thesis of the game.

- For every $t \neq t_{0}$ there is a unique $t^{\prime}$ such that $t^{\prime} S t$.

- For every $t$ and $t^{\prime}$ in $T$, if $t S t^{\prime}$ then $\left.\ell^{\prime} t^{\prime}\right)=(t)+1$.

- Given a play $\pi$ in $\mathrm{D}(\varphi)$ such that $p_{\pi}\left(M^{\prime}\right)=p_{\pi}(M)+1$ and $t, t^{\prime}$ respectively labelled with $M$ and $M^{\prime}$, then $t S t^{\prime}$.

Many metalogical results concerning dialogical games are obtained by considering them by leaving the level of rules and plays and moving to the level of strategies. 
Among these results, significant ones are given in terms of the existence of winning strategies for a player. We now define these notions and give examples of results.

A strategy for Player $\mathbf{X}$ in $\mathrm{D}(\varphi)$ is a function which assigns an $\mathbf{X}$ move $M$ to every non terminal play $\pi$ with a $\mathbf{Y}$ move as last member such that extending $\pi$ with $M$ results in a play. An $\mathbf{X}$ strategy is winning if playing according to it leads to $\mathbf{X}$ 's victory no matter how $\mathbf{Y}$ plays.

A strategy can be considered from the viewpoint of extensive forms: the extensive form of an $\mathbf{X}$ strategy $\sigma$ in $\mathrm{D}(\varphi)$ is the tree-fragment $\mathrm{E}_{\varphi, \sigma}=\left(T_{\sigma}, l_{\sigma}, S_{\sigma}\right)$ of $\mathrm{E}_{\varphi}$ such that:

i. The root of $E_{\varphi, \sigma}$ is the root of $E_{\varphi}$.

ii. Given a node $t$ in $\mathbf{E}_{\varphi}$ labelled with an $\mathbf{X}$ move, we have that $t S_{\sigma} t^{\prime}$ whenever $t S t^{\prime}$.

iii. Given a node $t$ in $\mathbf{E}_{\varphi}$ labelled with a $\mathbf{Y}$ move and with at least one $t^{\prime}$ such that $t S t^{\prime}$, then there is a unique $\sigma(t)$ in $T_{\sigma}$ where $t S_{\sigma} \sigma(t)$ and $\sigma(t)$ is labelled with the $\mathbf{X}$ move prescribed by $\sigma$.

Here are some examples of results which pertain to the level of strategies. ${ }^{35}$

- Winning $\mathbf{P}$ strategies and leaves. Let $\mathrm{w}$ be a winning $\boldsymbol{P}$ strategy in $\mathrm{D}(\varphi)$. Then every leaf in $\mathrm{E}_{\varphi, \mathrm{w}}$ is labelled with a $\boldsymbol{P}$ signed atomic sentence.

- Determinacy. There is a winning $\boldsymbol{X}$ strategy in $\mathrm{D}(\varphi)$ if and only if there is no winning $\boldsymbol{Y}$ strategy in $\mathrm{D}(\varphi)$.

- Soundness and Completeness of Tableaux. Consider first-order tableaux and firstorder dialogical games. There is a tableau proof for $\varphi$ if and only if there is a winning $\boldsymbol{P}$ strategy in $\mathrm{D}(\varphi)$.

By soundness and completeness of the tableau method with respect to modeltheoretical semantics, it follows that existence of a winning $\mathbf{P}$ strategy coincides with validity: There is a winning $\boldsymbol{P}$ strategy in $\mathrm{D}(\varphi)$ if and only if $\varphi$ is valid.

\section{Examples of Extensive Forms.}

Extensive forms of dialogical games and of strategies are infinitely generated trees (trees with infinitely many branches). Thus it is not possible to actually write them down. But an illustration remains helpful, so we add Figures 1 and 2 below.

Figure 1 partially represents the extensive form of the dialogical game for the formula $\forall x(Q x \rightarrow Q x)$. Every play in this game is represented as a branch in the extensive

35 These results are proven, together with others, in Clerbout (2013). 
form: we have given an example with the leftmost branch which represents one of the simplest and shortest plays in the game. The root of the extensive form is labelled with the thesis. After that, the Opponent has infinitely many possible choices for her repetition rank: this is represented by the root having infinitely many immediate successors in the extensive form. The same goes for the Proponent's repetition rank, and every time a player is to choose an individual constant.

Figure 2 partially represents the extensive form of a strategy for the Proponent in this game. It is a fragment of the tree of Figure 1 where each node labelled with an $\mathbf{O}$ move has at most one successor. We do not keep track of all the possible choices for $\mathbf{P}$ any more: every time the Proponent has a choice in the game, the strategy selects exactly one of the possible moves. But since all the possible ways for the Opponent to play must be taken into account by a strategy, the other ramifications are kept. In our example, the strategy prescribes to choose the same repetition rank as the Opponent. Of course there are infinitely many other strategies available for $\mathbf{P}$.

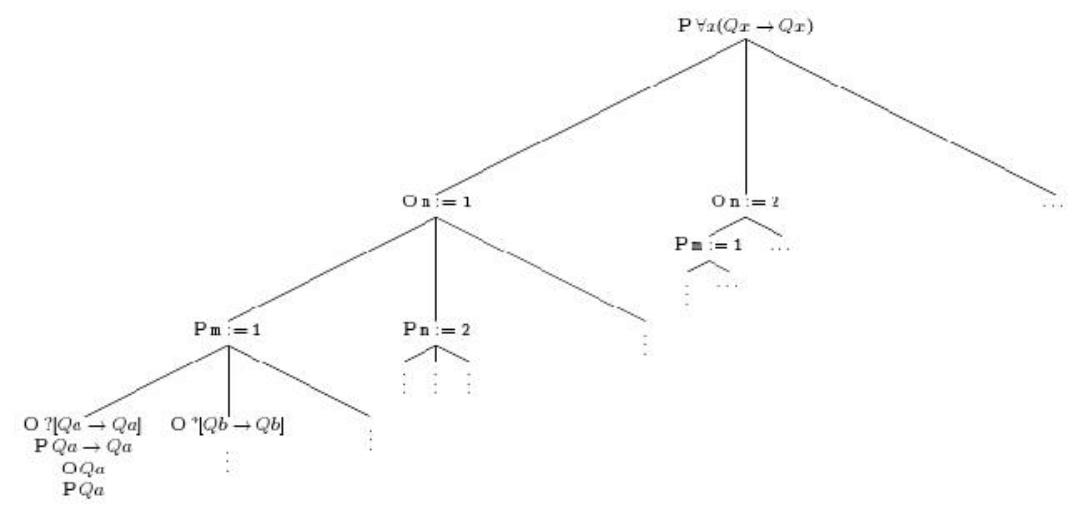

Figure 1.

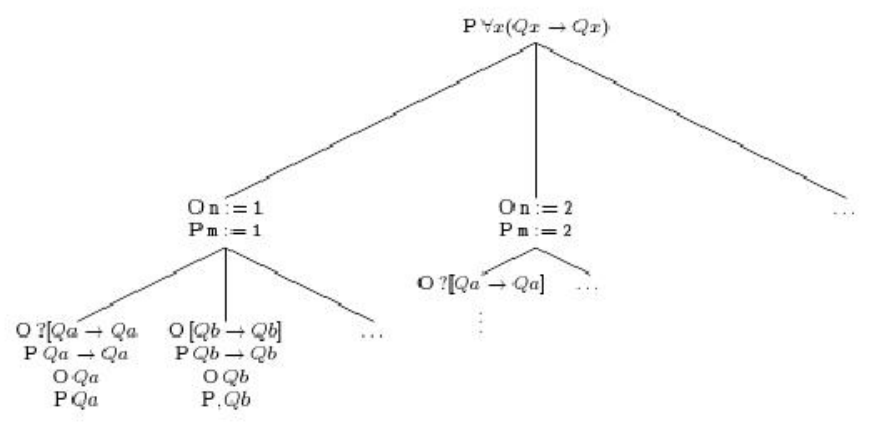

Figure 2. 


\section{Appendix 2: Definitional Equality and the Equality-Predicate}

\section{A.2.1 \\ Definitional Equality}

Reflexivity within set

\begin{tabular}{|l|l|l|}
\hline Posit & Challenge & Defence \\
\hline $\mathbf{X}-!-\dot{A}:$ set & $\mathbf{Y}-?_{\text {set }^{-}}$refl & $\mathbf{X}-!-A=A$ set \\
& & \\
\hline
\end{tabular}

Symmetry within set

\begin{tabular}{|l|l|l|}
\hline Posit & Challenge & Defence \\
\hline $\mathbf{X}-!-A \dot{=} B:$ set & $\mathbf{Y}-?_{\mathrm{B}^{-}}$symm & $\mathbf{X}-!-B=A:$ set \\
& & \\
& & \\
\end{tabular}

Transitivity within set

\begin{tabular}{|c|c|c|}
\hline Posit & Challenge & Defence \\
\hline $\mathbf{X}-!-A=B:$ set & $\mathbf{Y}-?_{\mathrm{A}^{-}}$trans & $\mathbf{X}-!-A=C:$ set \\
$\mathbf{X}-!-B=C:$ set & & \\
\hline
\end{tabular}

Reflexivity within $\boldsymbol{A}$

\begin{tabular}{|l|l|l|}
\hline Posit & Challenge & Defence \\
\hline $\mathbf{X}-!-\dot{a}: \boldsymbol{A}$ & Y-? a refl & $\mathbf{X}-!-a=a: A$ \\
& & \\
\hline
\end{tabular}

Symmetry within $\boldsymbol{A}$

\begin{tabular}{|l|l|l|}
\hline Posit & Challenge & Defence \\
\hline $\mathbf{X}-!-a=b: A$ & $\mathbf{Y}-?_{b^{-}}$symm & $\mathbf{X}-!-b=a: A$ \\
& & \\
\hline
\end{tabular}

Transitivity within $\boldsymbol{A}$

\begin{tabular}{|c|c|c|}
\hline Posit & Challenge & Defence \\
\hline $\begin{aligned} \mathbf{X}-!-a=b: A \\
\mathbf{X}-!-b=c: A\end{aligned}$ & $\mathbf{Y}-?_{a}-$ trans & $\mathbf{X}-!-a=c: A$ \\
& & \\
\hline
\end{tabular}


Simple extensionality

\begin{tabular}{|l|l|l|}
\hline Posit & Challenge & Defence \\
\hline $\mathbf{X}-!-A \dot{=} B:$ set & $\mathbf{Y}-?_{\mathrm{ext}}-a: A$ & $\mathbf{X}-!-a: B$ \\
& & \\
\hline
\end{tabular}

Double extensionality

\begin{tabular}{|l|l|l|}
\hline Posit & Challenge & Defence \\
\hline $\mathbf{X}-!-A \dot{=} B:$ set & $\mathbf{Y}-?_{\mathrm{d}-\mathrm{ext}-} a=b: A$ & $\mathbf{X}-!-a=b: B$ \\
& & \\
\hline
\end{tabular}

Substitution $B(x)$

\begin{tabular}{|l|l|l|}
\hline \multicolumn{1}{|l|}{ Posit } & Challenge & Defence \\
\hline $\mathbf{X}-!-B(x): \operatorname{set}(x: A)$ & $\mathbf{Y}-?_{\mathrm{B}(\mathrm{x}) \text {-subst }} a=c: A$ & $\mathbf{X}-!-B(a)=B(c):$ set \\
& & \\
\hline
\end{tabular}

Substitution $b(x)$

\begin{tabular}{|l|l|l|}
\hline Posit & Challenge & Defence \\
\hline $\mathbf{X}-!-b(x): B(x)(x: A)$ & $\mathbf{Y}-?_{\mathrm{b}(\mathrm{x}) \text {-subst }}-a=c: A$ & $\mathbf{X}-!-b(a)=b(c): B(a)$ \\
& & \\
\hline
\end{tabular}

A.2.2

The Equality-Predicate

Formation of the Equality Predicate

\begin{tabular}{|c|c|c|}
\hline Posit & Challenge & Defence \\
\hline $\mathbf{X}-!-\mathrm{I}(\mathrm{A}, \vec{a}, b): s e t$ & $\begin{array}{l}\mathbf{Y} ?^{1}{ }^{\mathrm{F}-} \\
\text { or } \\
\mathbf{Y} ?^{2}{ }_{\mathrm{F}-\mathrm{I}} \\
\text { or } \\
\mathbf{Y} ?^{3}{ }_{\mathrm{F}-\mathrm{I}} \\
\text { [the challenger has the choice] }\end{array}$ & $\begin{array}{c}\mathbf{X}-!-A: \text { set } \\
a: A \\
b: A\end{array}$ \\
\hline
\end{tabular}


From definitional equality to the equality-predicate

\begin{tabular}{|l|l|l|}
\hline \multicolumn{1}{|l|}{ Posit } & Challenge & Defence \\
\hline \multicolumn{1}{|l}{$\mathbf{X}-!-\dot{a}=b: A$} & $\mathbf{Y}-?_{\text {def-pred }^{-}} a: A$ & $\mathbf{X}-!-\mathrm{p}: \mathrm{I}(\mathrm{A}, a, b)$ \\
& & \\
\hline
\end{tabular}

Substitution for the equality-predicate

\begin{tabular}{|c|l|l|}
\hline Posit & Challenge & Defence \\
\hline $\mathbf{X}-!-\mathrm{p}: \mathrm{I}(A, a, b)$ & & \\
$\mathbf{X}-! a: A$ & & $\mathbf{X}-!-\mathrm{q}: B(b)$ \\
$\mathbf{X}-!-\mathrm{q}: B(a)$ & $\mathbf{Y}-?_{\text {-pred.-susbst }-b: A}$ & \\
& & \\
\hline
\end{tabular}




\section{Literature}

Blass, A. (1992). "A Game Semantics for Linear Logic". Annals of Pure and Applied Logic 56, 1992.

Carnap, R. (1947). Meaning and Necessity, Chicago: Chicago University Press, 1947.

Clerbout, N. (2013). Etude sur quelques sémantiques dialogiques. Concepts fondamentaux et éléments de metathéorie. PHD thesis, Lille/Leiden: Universities of Lille 3 and Leiden, 2013.

Clerbout, N. / Gorisse, M.-H. / Rahman, S. (2011). "Context-sensitivity in Jain Philosophy. A dialogical study of Siddharsigani's Commentary on the Handbook of Logic". Journal of Philosophical Logic 40:5, 2011.

Detlefsen, M. (1992). "Poincaré Against the Logicians". Synthese 90:3, 1992.

Felscher, W. (1985). "Dialogues as a foundation for intuitionistic logic". In Gabbay, D. and Guenthner, F. (eds.), Handbook of Philosophical Logic Volume 3, Dordrecht: Kluwer, 1985.

Fiutek, V. / Rückert, H. / Rahman, S. (2010). “A Dialogical Semantics for Bonanno's System of Belief Revision". In Bour, P. et al. (eds.), Constructions, London: College Publications, 2010.

Fontaine, M. (2013). Argumentation et engagement ontologique de l'acte intentionnel. Pour une réflexion critique sur l'identité dans les logiques intentionnelles explicites. PHD thesis, Lille: University of Lille 3, 2013.

Granström, J. (2011). Treatise on Intuitionistic Type Theory, Dordrecht: Springer, 2011.

Hintikka, J (1973). Logic, Language-Games and Information, Oxford: Clarendon Press, 1973.

Kamlah, W. / Lorenzen, P. (1972). Logische Propädeutik, Suttgart/Weimar: Metzler, Second edition, 1972.

Kamlah, W. / Lorenzen, P. (1984). Logical Propaedeutic, English translation of Kamlah/Lorenzen (1972) by H. Robinson, University Press of America, 1984.

Keiff, L. (2004a). "Heuristique formelle et logiques modales non normales". Philosophia Scientiae 8:2, 2004.

Keiff, L. (2004b). "Introduction à la dialogique modale et hybride". Philosophia Scientiae 8:2, 2004.

Keiff, L. (2007). Le Pluralisme Dialogique. Approches dynamiques de l'argumentation formelle. PHD thesis, Lille: Université de Lille, 2007. 
Keiff, L. (2009). "Dialogical Logic". Sanford Encyclopedia of Philosophy, online (accessed 2013), 2009.

Lorenz, K. (1970). Elemente der Sprachkritik Eine Alternative zum Dogmatismus und Skeptizismus in der Analytischen Philosophie, Frankfurt:Suhrkamp Verlag, 1970.

Lorenz, K. (2001). "Basic objectives of dialogue logic in historical perspective". In Rahman/Rückert (2001), 2001.

Lorenz, K. (2008). Dialogischer Konstruktivismus, Berlin/New York: de Gruyter, 2008.

Lorenz, K. (2010a). Philosophische Variationen: Gesammelte Aufsatze Unter Einschluss Gemeinsam Mit Jurgen Mittelstrass Geschriebener Arbeiten Zu Platon Und Leibniz, Berlin/New York: De Gruyter, 2010.

Lorenz, K. (2010b). Logic, Language and Method - On Polarities in Human Experience, Berlin/New York: de Gruyter, 2010.

Lorenz, K. / Mittelstrass, J. (1966). "Theaitetos Fliegt. Zur Theorie Wahrer Und Fascher Sätze Bei Platon”. Archiv für Geschichte der Philosophie 48:1-3, 1966.

Lorenz, K. / Mittelstrass, J. (1967). "On Rational Philosophy of Language. The programme in Plato’s Cratylus Reconsidered”. Mind 76:301, 1967.

Lorenzen P. (1955). Einführung in die operative Logik und Mathematik, Berlin/Göttingen/Heidelberg: Springer, 1955.

Lorenzen, P. (1962). "Gleichheit und Abstraktion”. Ratio 4, 1962.

Lorenzen P. (1973). "Semantisch Normierte Orthosprachen". In Kambartel, F. and Mittelstrass, J. (eds.), Zum normativen Fundament der Wissenschaft, Frankfurt/Main: Athenäum-Verlag, 1973.

Lorenzen P. / Lorenz K. (1978). Dialogische Logik, Darmstadt: Wissenschaftliche Buchgesellschaft, 1978.

Lorenzen P. / Schwemmer O. (1975). Konstruktive Logik Ethik und Wissenschaftstheorie, Mannheim: Bibliographisches Institut, Second edition, 1975.

Magnier, S. (2013). Approche dialogique de la dynamique épistémique et de la condition juridique, London: College Publications, 2013.

Marion, M. / Rückert, H. (2012). “Aristotle on Universal Quantification”. Unpublished, forthcoming.

Martin-Löf, P. (1984). Intuitionistic Type Theory - Notes by Giovanni Sambin of a series of lectures given in Padua, June 1980, Naples: Bibliopolis, 1984. 
Nordström, B. / Petersson, K. / Smith, J. M. (1990). Programming in Martin-Löf 's Type Theory - An Introduction, Oxford: Oxford University Press, 1990.

Poincaré, H. (1902). La science et l'hypothèse, Paris: Flammarion, 1902.

Poincaré, H. (1906a). "Les mathématiques et la logique". Revue de Métaphysique et de Morale 14, 1906.

Poincaré, H. (1906b). "Les mathématiques et la logique". Revue de Métaphysique et de Morale 14, 1906.

Popek, A. (2011). "Logical dialogues from Middle Ages". In Barés et al. (eds), Logic of Knowledge. Theory and Applications, London: College Publications, 2011.

Primiero, G. (2008). Information and Knowledge. A Constructive Type-theoretical Approach, Dordrecht: Springer, 2008.

Rahman, S. (1993). Über Dialogue, Protologische Kategorien und andere Seltenheiten, Frankfurt/Paris/New York: P. Lang, 1993.

Rahman, S. (2009). "A non normal logic for a wonderful world and more". In van Benthem et al. (eds.), The Age of Alternative Logics, Second edition, Dordrecht: KluwerSpringer, 2009.

Rahman, S. (2012). "Negation in the Logic of First Degree Entailment and Tonk: a Dialogical Study”. In. Rahman et al. (2012), 2012.

Rahman, S. / Clerbout, N. / McConaughey, Z. (2013). "On play-objects in dialogical games. Towards a Dialogical approach to Constructive Type Theory". To appear in Allo, P. et al. (eds.), Tribute to Jean-Paul van Bendegem, London: College Publications, 2013.

Rahman, S. / Clerbout, N. / Keiff, L. (2009). "On Dialogues and Natural Deduction”. In Rahman, S. and Primiero, G. (eds.), Acts of Knowledge - History, Philosophy, Logic, London: College Publications, 2009.

Rahman, S. / Keiff, L. (2004). "On How to be a Dialogician”. In Vanderveken, D. (ed.), Logic, Thought and Action, Dordrecht: Kluwer, 2005.

Rahman, S. / Keiff, L. (2010). "La Dialectique entre logique et rhétorique". Revue de Métaphysique et de Morale 66:2, 2010.

Rahman, S. / Primiero, G. /Marion, M. (2012). The Realism-Antirealism Debate in the Age of Alternative Logics, Dordrecht: Springer, 2012.

Rahman, S. / Rückert, H. (2001). Rahman, S. and Rückert, H. (eds.), New Perspectives in Dialogical Logic. Synthese 127:1-2, special volume. 
Rahman, S. / Rückert, H. (2011). "Eine neue dialogische Semantik für linear Logik”. In Rückert (2011), London: College Publications, 2011.

Rahman, S. / Tulenheimo, T. (2009). "From Games to Dialogues and Back: Towards a General Frame for Validity". In Majer, O. and al. (eds.), Games: Unifying Logic, Language and Philosophy, Dordrecht: Springer, 2009.

Ranta, A. (1988). "Propositions as games as types". Synthese 76, 1988.

Ranta, A. (1994). Type-Theoretical Grammar, Clarendon Press, 1994.

Read, S. (2008). "Harmony and modality". In Dégremont, C. and al. (eds.), Dialogues, Logics and Other Strange Things: Essays in Honour of Shahid Rahman, London: College Publications, 2008.

Redmond, J. (2010). Logique dynamique de la fiction. Pour une approche dialogique, London: College Publications, 2010.

Redmond, J. / Fontaine, M. (2011). How to Play Dialogues. An Introduction to Dialogical Logic, London: College Publications, 2011.

Rückert, H. (2001). "Why Dialogical Logic?” In Wansing, H. (ed.), Essays on NonClassical Logic, Singapore: World Scientific, 2001.

Rückert, H. (2011a). Dialogues as a dynamic framework for logic, London: College Publications, 2011.

Rückert, H. (2011b). "The Conception of Validity in Dialogical Logic". Talk at the workshop Proofs and Dialogues, Tübingen, 2011.

Sundholm, G. (1983a). "Constructions, proofs and the meaning of the logical constants". Journal of Philosophical Logic 12:2, 1983.

Sundholm, G. (1983b). "Systems of deduction". In Gabbay, D. and Guenthner, F. (eds.), Handbook of Philosophical Logic Volume 1, Dordrecht: Reidel, 1983.

Sundholm, G. (1986). "Proof-Theory and Meaning". In Gabbay, D. and Guenthner, F. (eds), Handbook of Philosophical Logic Volume 3, Dordrecht: Reidel, 1986.

Sundholm, G. (1997). "Implicit epistemic aspects of constructive logic". Journal of Logic, Language, and Information 6:2, 1997.

Sundholm, G. (1998). "Inference versus Consequence". In Childers, T. (ed.), The Logica Yearbook 1997, Prague: Filosofia, 1998.

Sundholm, G. (2001). “A Plea for Logical Atavism”. In Majer, O. (ed.), The Logica Yearbook 2000, Prague: Filosofia, 2001.

Sundholm, G. (2009). “A Century of Judgment and Inference: 1837-1936”. In Haapa- 
ranta, L. (ed.), The Development of Modern Logic, Oxford: Oxford University Press, 2009.

Sundholm, G. (2013). "Containment and Variation; Two Strands in the Development of Analyticity from Aristotle to Martin-Löf". In van der Schaar, M. (ed.), Judgement and the Epistemic Foundation of Logic, Dordrecht: Springer, 2013.

Tulenheimo, T. (2011). "On Some Logic Games in Their Philosophical Context". In Lecomte, A. and Tronçon, S. (eds.), Ludics, Dialogues and Interaction. PRELUDE Project 2006-2009. Revised Selected Papers, Berlin/Heidelberg: Springer, 2011. 